Cite this: Phys. Chem. Chem. Phys., 2014, 16, 7786

Received 13th January 2014, Accepted 5th March 2014

DOI: $10.1039 / c 4 c p 00869 c$

www.rsc.org/pccp

\section{A facile and generic method to improve cathode materials for lithium-ion batteries via utilizing nanoscale surface amorphous films of self-regulating thickness $\dagger$}

\author{
Jiajia Huang and Jian Luo*
}

\begin{abstract}
As a facile and generic surface modification method, a unique class of surface amorphous films (SAFs) is utilized to significantly improve the rate performance and cycling stability of cathode materials for lithium-ion batteries. These nanoscale SAFs form spontaneously and uniformly upon mixing and annealing at a thermodynamic equilibrium, and they exhibit self-regulating or "equilibrium" thickness due to a balance of attractive and repulsive interfacial interactions acting on the films. Especially, spontaneous formation of nanoscale $\mathrm{Li}_{3} \mathrm{PO}_{4}$-based SAFs has been demonstrated in two proof-ofconcept systems, $\mathrm{LiCOO}_{2}$ and $\mathrm{LiMn}_{1.5} \mathrm{Ni}_{0.5} \mathrm{O}_{4}$, which have an equilibrium thickness of $\sim 2.9 \mathrm{~nm}$ and $\sim 2.5 \mathrm{~nm}$, respectively. At a high discharge rate of $25 \mathrm{C}$, these $\mathrm{Li}_{3} \mathrm{PO}_{4}$-based SAFs improve the discharge capacity by $\sim 130 \%$ for $\mathrm{LiCoO}_{2}$ and by $\sim 40 \%$ for $\mathrm{LiMn}_{1.5} \mathrm{Ni}_{0.5} \mathrm{O}_{4}$, respectively. Furthermore, these SAFs improve the cycling stability and reduce capacity fading of both $\mathrm{LiCoO}_{2}$ and $\mathrm{LiMn}_{1.5} \mathrm{Ni}_{0.5} \mathrm{O}_{4}$. At an elevated temperature of $55{ }^{\circ} \mathrm{C}, \mathrm{Li}_{3} \mathrm{PO}_{4}$-based SAFs can help to maintain $\sim 90 \mathrm{~mA} \mathrm{~h} \mathrm{~g}{ }^{-1}$ discharge capacity of the high-voltage material $\mathrm{LiMn}_{1.5} \mathrm{Ni}_{0.5} \mathrm{O}_{4}$ after 350 cycles at a relatively high chargedischarge rate of $1 \mathrm{C}$. Further mechanistic studies suggest that these SAFs reduce the interfacial charge transfer resistance and suppress the growth of the solid-electrolyte interphase. This facile method can be utilized to improve a broad range of cathode and anode materials. A thermodynamic framework is proposed, which can be used to guide future experiments of other material systems.
\end{abstract}

\section{Introduction}

Surface coatings and modifications are widely used to improve the performance of electrode materials for lithium-ion batteries. Notably, a series of recent studies have demonstrated that nanoscale surface oxide coatings made by atomic layer deposition (ALD) can improve the cycling stability and other performance properties of cathode materials. ${ }^{1-8}$ Although ALD can be used to make uniform nanoscale oxide coatings with high levels of control, this technique requires special equipment. Alternatively, numerous prior studies attempted to "coat" battery materials by mixing the active materials with coating materials by wet chemistry methods or simply dry mixing, where the specimens were typically subjected to subsequent annealing. ${ }^{9-27}$ It is hoped that uniform nanoscale surface coatings might form, which were not always guaranteed. Consequently, substantial

Department of NanoEngineering, Program of Materials Science and Engineering, University of California, San Diego, La Jolla, CA 92093-0448, USA.

E-mail:jluo@alum.mit.edu

$\dagger$ Electronic supplementary information (ESI) available. See DOI: 10.1039/ c4cp00869c trials and errors were required and the success of such an approach largely depended on luck.

This study aims to establish an innovative coating strategy through a facile "mixing and annealing" route via utilizing a unique class of equilibrium-thickness surface amorphous films (SAFs). Compared with conventional approaches, these nanoscale SAFs form spontaneously with self-regulating and uniform thickness. Using $\mathrm{LiCoO}_{2}$ and $\mathrm{LiMn}_{1.5} \mathrm{Ni}_{0.5} \mathrm{O}_{4}$ as two proof-of-concept systems, we have demonstrated that nanoscale $\mathrm{Li}_{3} \mathrm{PO}_{4}$-based SAFs can form these spontaneously and uniformly at thermodynamic equilibria, which have subsequently improved the rate performance and cycling stability of the two cathode materials via reducing the interfacial charge transfer resistance and suppressing the growth of the solidelectrolyte interphase (SEI).

This study was primarily motivated by the discovery of the thermodynamic stabilization of nanoscale SAFs in a variety of oxide systems. $^{28-36}$ These SAFs are free-surface counterparts to a class of equilibrium-thickness intergranular films (IGFs) that have been widely observed at ceramic grain boundaries and metaloxide interfaces. ${ }^{35-40}$ Thermodynamically, these equilibriumthickness SAFs (or IGFs) can be considered as two-dimensional 
surface (or interfacial) "phases," which have been named as "complexions" by Tang, Carter and Cannon based on arguments that they are not "phases" according to the rigorous Gibbs definition and they cannot exist without abutting bulk phases. $^{35,41-46}$ These SAFs (and analogous IGFs) have several distinct characteristics. First, they form spontaneously by mixing and annealing at a thermodynamic equilibrium. Second, they adopt a self-regulating or "equilibrium" thicknesses on the order of $1 \mathrm{~nm}$. Third, they are neither fully crystalline nor completely amorphous (despite being called "amorphous" films). Fourth, they can possess structures and compositions that are neither found nor stable as bulk phases (e.g., the average film composition can lie in a bulk miscibility gap). Fifth, they can form at a thermodynamic equilibrium when the corresponding bulk liquid or glass phase is no longer stable. Thus, they can be utilized to achieve superior properties unattainable by conventional bulk phases or nanomaterials. $^{28}$

In $2005, \mathrm{Li}$ and Garofalini ${ }^{47}$ first suggested that such nanoscale "amorphous" interfacial films can act as rapid $\mathrm{Li}$ ion transport pathways via molecular dynamics simulations of $\mathrm{V}_{2} \mathrm{O}_{5}$. In 2008, De Jonghe and co-workers showed that the formation of 1-4 nm thick, impurity-based IGFs in lanthanum phosphate solid-state electrolytes increased the proton conductivity by more than an order of magnitude. ${ }^{48}$ Later, nanoscale, phosphate-based IGFs, along with SAFs of similar character, have also been observed in partially-sintered $\mathrm{LiFePO}_{4}$ and $\mathrm{LiMn}_{1.5} \mathrm{Ni}_{0.5} \mathrm{O}_{4}$ electrodes. ${ }^{29,49,50}$ In 2009, Tang, Chiang and Carter suggested that nanoscale SAFs can form in $\mathrm{LiMPO}_{4}$ ( $\mathrm{M}=\mathrm{Fe}, \mathrm{Mn}, \mathrm{Co}, \mathrm{Ni})$ olivines and critically affect the phase transformation during electrochemical cycling via a diffuseinterface (phase-field) model. ${ }^{51}$ In the same month, Kang and Ceder reported that the formation of a glassy $\mathrm{Li}_{4} \mathrm{P}_{2} \mathrm{O}_{7}$-like "fast ion-conducting surface phase" $(<5 \mathrm{~nm})$ in "off-stoichiometric" $\mathrm{LiFePO}_{4}$ can help to achieve ultrafast discharging. ${ }^{52}$ Although this report $^{52}$ led to great excitement, it too resulted in a debate. ${ }^{53,54}$ A technical comment ${ }^{53}$ suggested: "There is no reason to believe that $\mathrm{Li}_{4} \mathrm{P}_{2} \mathrm{O}_{7}$ impurity will coat the particles. Instead, impurities usually form nanoparticles that stick on the surfaces." The follow-up study by Kayyar et $a .^{29}$ showed that such coatings can form and they are likely equilibriumthickness SAFs. In 2012, Chong et al. carefully re-examined Kang and Ceder's material and benchmarked it with carboncoated $\mathrm{LiFePO}_{4}$; their study confirmed the effects of the $\mathrm{Li}_{4} \mathrm{P}_{2} \mathrm{O}_{7}$-based "fast ion-conducting surface phase" in improving the rate performance despite that the electronic conductivity was not increased. ${ }^{49}$

It is also worth noting that a series of prior studies coated amorphous oxides (such as $\mathrm{Al}_{2} \mathrm{O}_{3}, \mathrm{ZnO}, \mathrm{Bi}_{2} \mathrm{O}_{3}, \mathrm{AlPO}_{4}, \mathrm{MgO}$, $\mathrm{CoPO}_{4}, \mathrm{CeO}_{2}, \mathrm{ZrO}_{2}$, and $\mathrm{SiO}_{2}$ ) on a variety of cathode particles to improve cycling and rate performances. ${ }^{11-20}$ These coatings were made by a special solution-based sol-gel coating method. Some of these coatings remained uniform and amorphous after subsequent annealing at $400-600{ }^{\circ} \mathrm{C}$, so that they must be at least metastable. However, it is unknown whether they are true equilibrium SAFs; in fact, many of these systems are unlikely equilibrium SAFs because of the high surface energies of the film-forming oxides (as discussed in the next section). Thus, these surface coatings were likely kinetically stabilized (a.k.a. they were not the equilibrium SAFs that would form spontaneously with self-regulating thickness upon annealing). Nonetheless, this series of studies ${ }^{11-20}$ demonstrated the great potential of using nanoscale amorphous coatings to improve the performance of cathode materials.

Three more recent studies attempted to coat lithium phosphates on the surfaces of various cathode materials with some success. In 2011, Sun and Dillon showed that $\mathrm{Li}_{3} \mathrm{PO}_{4}$-based surficial films could form on $\mathrm{LiCoO}_{2}$ in specimens annealed and quenched from $850{ }^{\circ} \mathrm{C}$, which improved the rate performance; however, the authors noted that the surficial films formed under that specific condition were "not necessarily continuous or constant thickness" and were thicker $(\sim 10 \mathrm{~nm})$ where they were present. ${ }^{22}$ In 2012 , Li et al. coated "nano$\mathrm{Li}_{3} \mathrm{PO}_{4}$ " on $\mathrm{LiMn}_{2} \mathrm{O}_{4}$ to enhance the cycling stability at an evaluated temperature; ${ }^{25}$ in their work, the specimens were calcined at a lower temperature of $450{ }^{\circ} \mathrm{C}$, which resulted in a $\sim 10 \mathrm{~nm}$ thick crystalline nano- $\mathrm{Li}_{3} \mathrm{PO}_{4}$ phase (presumably not uniform films) on $\mathrm{LiMn}_{2} \mathrm{O}_{4}$. In 2013, Chong et al. reported "surface stabilized $\mathrm{LiMn}_{1.5} \mathrm{Ni}_{0.5} \mathrm{O}_{4}$ " by $\mathrm{Li}_{4} \mathrm{P}_{2} \mathrm{O}_{7}$-based coatings with improved rate capability and cycling stability at room temperature; ${ }^{50}$ in this study, the surface coatings appear to be uniform and thicker $(8-10 \mathrm{~nm})$, which the authors referred to as "a coating layer of $\mathrm{Li}_{4} \mathrm{P}_{2} \mathrm{O}_{7}$ crystallite coexisting with a little $\mathrm{Li}_{3} \mathrm{PO}_{4}$ ". It appeared that these phosphate-based coatings obtained under the specific processing conditions used in the three above-mentioned studies were not fully equilibrium SAFs that would from continuously with nearly constant thickness in a typical range of $0.5-5 \mathrm{~nm} .^{28}$

The assembly of the above-discussed recent studies motivated us to use $\mathrm{Li}_{3} \mathrm{PO}_{4}$-based SAFs on $\mathrm{LiCoO}_{2}$ and $\mathrm{LiMn}_{1.5} \mathrm{Ni}_{0.5} \mathrm{O}_{4}$ as two proof-of-concept systems to conduct a systematic and definite study, where we successfully found the processing conditions to form SAFs with a self-regulating (equilibrium) thickness of $\sim 2.9 \mathrm{~nm}$ and $\sim 2.5 \mathrm{~nm}$, respectively. It is imperative to conduct careful statistical measurements to prove the formation of uniform SAFs with nearly constant (equilibrium) thickness and then demonstrate that such SAFs can be utilized to improve the rate performance and cycling stability; such a critical and definite study has never been conducted before, which warrants the current work.

A further objective of this study is to investigate the underlying mechanisms of how such surface films/phases (regardless they are equilibrium or not) improve the performance of cathode materials. Kang and Ceder proposed that the $\mathrm{Li}_{4} \mathrm{P}_{2} \mathrm{O}_{7}$-like "fast ion-conducting surface phase" can serve as a "beltway" to effectively improve ion transport because of the one-dimensional lithium ion conduction in $\mathrm{LiFePO}_{4} \cdot{ }^{52}$ Sun and Dillon showed that $\mathrm{Li}_{3} \mathrm{PO}_{4}$-based surficial films, although they were not continuous with a constant thickness, significantly improved the rate performance of a more isotropic material, $\mathrm{LiCoO}_{2}$, with twodimensional ion conduction; thus, they suggested that these films might enhance the rate capability by reducing concentration polarization at the particle surfaces. ${ }^{22}$ In this study, 
we found the processing conditions to form significantly more uniform $\mathrm{Li}_{3} \mathrm{PO}_{4}$-based SAFs on $\mathrm{LiCoO}_{2}$ with an equilibrium thickness of $\sim 2.9 \mathrm{~nm}$. Furthermore, we adopted a special technique developed by Creager and co-workers ${ }^{55}$ to show that the enhanced rate capability is not due to reduction in the concentration polarization; further impedance measurements suggested that these nanoscale SAFs may enhance the rate performance by reducing the interfacial charge transfer resistance. We further demonstrated that $\mathrm{Li}_{3} \mathrm{PO}_{4}$-based SAFs can enhance the rate performance of an even more isotropic material, spinel $\mathrm{LiMn}_{1.5} \mathrm{Ni}_{0.5} \mathrm{O}_{4}$, as well as significantly improve its cycling stability at an elevated temperature by protecting the electrode surfaces and suppressing the SEI growth.

\section{Thermodynamic model and theoretical analysis}

Here, we first present a thermodynamic model ${ }^{28}$ to assess the stabilization of $\mathrm{Li}_{3} \mathrm{PO}_{4}$-based SAFs in the two proof-of-concept systems and to explain the origin of the equilibrium thickness. This model can also be used to analyze and forecast the formation and stability of equilibrium-thickness SAFs in other battery materials in future studies.

A film will spontaneously "coat" on the surface of crystalline electrode particles if replacing a "clean" crystal-vapor surface of the electrode $\left(\gamma_{\mathrm{cv}}^{(0)}\right)$ with a film-vapor surface $\left(\gamma_{\mathrm{fv}}\right)$ and a crystalfilm interface $\left(\gamma_{\mathrm{cf}}\right)$ lowers the free energy:

$$
\gamma_{\mathrm{cf}}+\gamma_{\mathrm{fv}}<\gamma_{\mathrm{cv}}^{(0)}
$$

Eqn (1) suggests that we should select a coating material with a lower surface energy than that of the electrode material $\left(\gamma_{\mathrm{fv}}<\gamma_{\mathrm{cv}}^{(0)}\right)$ in order to form uniform coatings spontaneously. Moreover, the film-electrode interfacial energy $\left(\gamma_{\mathrm{cf}}\right)$ should be small; consequently, it is easier to make structurally-disordered coatings than crystalline coatings because the incoherent crystalcrystal interfacial energy is typically great. In the following text, we only consider structurally-disordered surface films; thermodynamically, we treat them as an undercooled quasi-liquid; thus, we replace all "f" with "l" in the subscripts (i.e., we rename $\gamma_{\mathrm{lv}}=\gamma_{\mathrm{fv}}$ and $\gamma_{\mathrm{cl}}=\gamma_{\mathrm{cf}}$ ) in the following text.

We should recognize three important nanoscale wetting phenomena, as follows. ${ }^{28,39}$ First, as schematically illustrated in Fig. 1(a), a nanometer-thick undercooled liquid film of thickness $h$ can be thermodynamically stabilized on a surface below the bulk solidus line if

$$
-\Delta \gamma \equiv \gamma_{\mathrm{cv}}^{(0)}-\left(\gamma_{\mathrm{cl}}+\gamma_{\mathrm{lv}}\right)>\Delta G_{\mathrm{amorph}}^{(\mathrm{vol})} \cdot h,
$$

where $\Delta G_{\mathrm{amorph}}^{(\mathrm{vol})}$ is the volumetric free-energy penalty for amorphization to form the undercooled liquid. The stabilization of impurity-based, quasi-liquid SAFs below the bulk solidus line is analogous to the well-known phenomenon of premelting (or surface melting) in unary systems ${ }^{56-58}$ as well as the prewetting in Cahn's critical point wetting model. ${ }^{59-61}$

Second, when the quasi-liquid film is nanometer-thick, the abutting crystal will inevitably impose significant partial
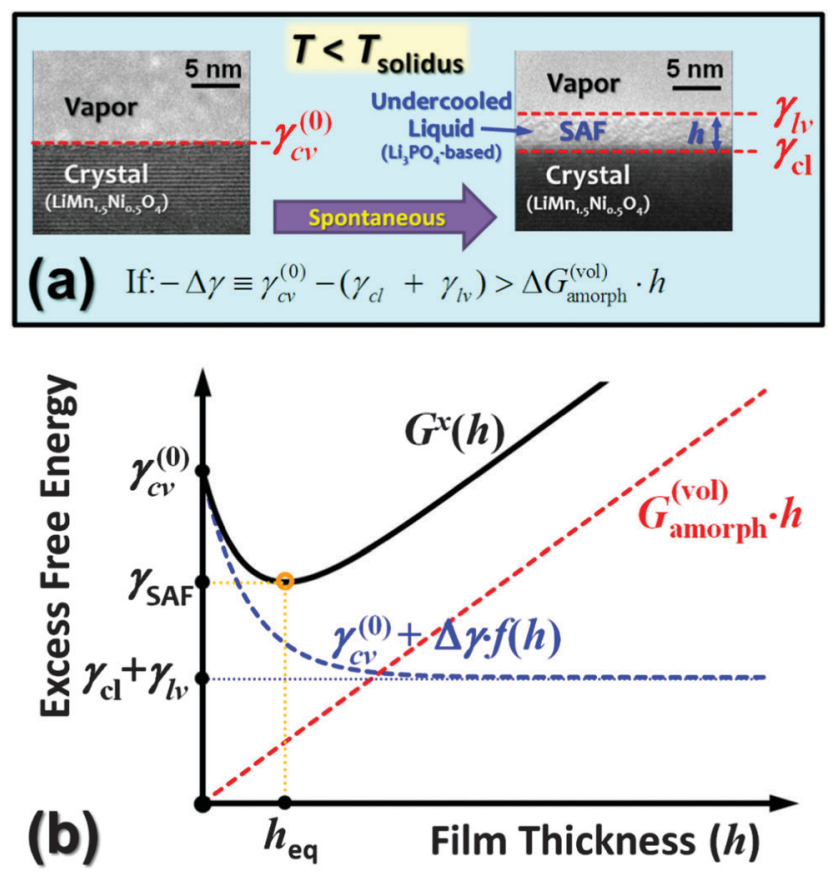

Fig. 1 (a) Schematic illustration of the thermodynamic principle for stabilizing a nanometer-thick SAF (being treated as an undercooled quasiliquid film) below the bulk solidus line. The two micrographs used in this schematic illustration are actual HRTEM images of the $\mathrm{LiMn}_{1.5} \mathrm{Ni}_{0.5} \mathrm{O}_{4}$ specimens with and without a $\mathrm{Li}_{3} \mathrm{PO}_{4}$-based SAF. (b) Schematic illustration of an excess free energy vs. film thickness curve. The equilibrium thickness $\left(h_{\text {eq }}\right)$ corresponds to the minimum in $G^{x}(h)$, which is determined by a trade-off between the reduction of surface energy as the thermodynamic driving force $(\Delta \gamma \cdot f(h))$ and the free-energy penalty for forming the undercooled liquid $\left(\Delta G_{\mathrm{amorph}}^{(\mathrm{vol})} \cdot h\right)$.

structural order into the film. ${ }^{28,62}$ Thus, these SAFs are not fully liquid/amorphous, despite that they were named as surface "amorphous" films. ${ }^{28}$ Interestingly, recent experimental and theoretical studies suggest that such partial structural order near the crystal-glass interfaces can promote ion transport to achieve higher ionic conductivity than both bulk crystal and glass phases. ${ }^{63,64}$

Third, when the film thickness is in the nanometer range, short-range, van der Waals (vdW) London dispersion, electrostatic, and other interfacial interactions will arise. Thus, the excess surface free energy can be written as:

$$
\begin{aligned}
G^{x}(h)= & \left(\gamma_{\mathrm{cl}}+\gamma_{\mathrm{lv}}\right)+\Delta G_{\mathrm{amorph}}^{(\mathrm{vol})} \cdot h+\sigma_{\text {short-range }}(h)+\sigma_{\mathrm{vdw}}(h) \\
& +\sigma_{\mathrm{elec}}(h)+\ldots,
\end{aligned}
$$

where all interfacial interactions are defined so that $\sigma_{\mathrm{i}}(h=+\infty)=0$ for consistence. The SAF will adopt an "equilibrium" thickness $\left(h_{\mathrm{eq}}\right)$ that minimizes the excess film free energy $\left(\mathrm{d} G^{x} /\left.\mathrm{d} h\right|_{h=h_{\mathrm{eq}}}=0\right)$, which represents a balance among attractive or repulsive pressures $\left(\mathrm{d} \sigma_{\mathrm{i}}(h) / \mathrm{d} h\right)$ acting on the film (Fig. 1(b)). Such a pressure-balance model was first proposed by Clarke to explain the equilibrium thickness of IGFs ${ }^{37,40,65}$ and later adapted to model SAFs. ${ }^{28,34,61,66}$ Cannon proposed that these impurity-based equilibrium-thickness IGFs and SAFs can 
be alternatively (and equivalently) interpreted as a special class of structurally-disordered multilayer adsorbates. ${ }^{67}$ It is important to note that the two interfaces are no longer independent and become one crystal-vapor surface thermodynamically under the condition that an equilibrium thickness is achieved, ${ }^{35}$ where equilibrium surface energy corresponds to the minimum of eqn (3):

$$
\gamma_{\mathrm{cv}}^{(\mathrm{eq})}=\gamma_{\mathrm{SAF}}=\min \left\{G^{x}(h)\right\}=G^{x}\left(h_{\mathrm{eq}}\right) \leq \gamma_{\mathrm{cv}}^{(0)} \equiv G^{x}(0) .
$$

The sum of the total interfacial pressure $\left(\sum_{i} \mathrm{~d} \sigma_{i}(h) / \mathrm{d} h\right)$ is the well-known Deryaguin disjoining pressure. 'Quantifying all interfacial interactions in eqn (3) for an oxide or phosphate system is infeasible. Alternatively, we can define a dimensionless interfacial coefficient $(f(h))$ based on the following equation:

$$
-\Delta \gamma \cdot[1-f(h)]=\sum_{i} \sigma_{i}(h) .
$$

Then, eqn (3) can be simplified to:

$$
G^{x}(h)-\gamma_{\mathrm{cv}}^{(0)}=\Delta \gamma \cdot f(h)+\Delta G_{\mathrm{amorph}}^{(\mathrm{vol})} \cdot h,
$$

which is schematically plotted in Fig. 1(b). Since the SAF formation should reduce the total surface excess free energy (i.e., $\left.G^{x}\left(h_{\mathrm{eq}}\right)<\gamma_{\mathrm{cv}}^{(0)}\right)$, eqn (2) can be refined to a more rigorous inequality:

$$
-\Delta \gamma \cdot f\left(h_{\mathrm{eq}}\right)>\Delta G_{\mathrm{amorph}}^{(\mathrm{vol})} \cdot h_{\mathrm{eq}}
$$

By definitions, the dimensionless interfacial coefficient changes from zero to one as the film thickness is varied from zero to infinity, i.e., $f(0)=0$ and $f(+\infty)=1$.

Then, we can use the above framework to assess the possible stabilization of $\mathrm{Li}_{3} \mathrm{PO}_{4}$-based, equilibrium-thickness SAFs on $\mathrm{LiCoO}_{2}$ and $\mathrm{LiMn}_{1.5} \mathrm{Ni}_{0.5} \mathrm{O}_{4}$, the two proof-of-concept systems adopted for this study. On one hand, the reduction in the interfacial energy (represented by $\Delta \gamma \cdot f(h)$, which should be negative for SAF formation,) is the thermodynamic driving force to form an SAF. In the current case, first-principle calculations estimated the $\gamma_{\mathrm{cv}}^{(0)}$ to be $\sim 1-3 \mathrm{~J} \mathrm{~m}^{-2}$ for $\mathrm{LiCoO}_{2}$ (ref. 68) and $\sim 1.7-3.1 \mathrm{~J} \mathrm{~m}^{-2}$ for $\mathrm{LiMn}_{1.5} \mathrm{Ni}_{0.5} \mathrm{O}_{4}$ (ref. 69), respectively. Thus, we adopt a median value of $\gamma_{\mathrm{cv}}^{(0)} \approx 2 \mathrm{~J} \mathrm{~m}^{-2}$ for our estimation. In comparison, the crystalline $\mathrm{Li}_{3} \mathrm{PO}_{4}$ surface energy was calculated to be $\sim 0.6-1.2 \mathrm{~J} \mathrm{~m}^{-2}$ by firstprinciple calculations, ${ }^{70}$ and the liquid/amorphous $\gamma_{\mathrm{lv}}$ for $\mathrm{Li}_{3} \mathrm{PO}_{4}$ should be less because some broken bonds can be satisfied by more relaxation; thus, we adopt the lower end value of the computed crystalline $\mathrm{Li}_{3} \mathrm{PO}_{4}$ surface energy for the liquid/amorphous surface energy: $\gamma_{\mathrm{lv}} \approx 0.6 \mathrm{~J} \mathrm{~m}^{-2}$. Since we know that $0<-\Delta \gamma<\left(\gamma_{\mathrm{cv}}^{(0)}-\gamma_{\mathrm{lv}}\right) \approx 1.4 \mathrm{~J} \mathrm{~m}^{-2}$ for SAF formation, we adopt a median value of $\Delta \gamma \approx-0.7 \mathrm{~J} \mathrm{~m}^{-2}$ as a rough estimation for the driving force for stabilizing an SAF in our systems.

On the other hand, there are two major attractive interactions that act to thin (diminish) the SAF. First, an attractive vdW London dispersion force is believed to restrain SAFs and IGFs from thickening above the bulk solidus line. ${ }^{28,30,37,39,40}$ In the current cases, the specific refractive indices and dielectric constants are not available for estimating the sign and strength of the dispersion force; however, the refractive index of the $\mathrm{LiPO}_{3}$ glass $(n \approx 1.5)$ is less than those of transition metal oxides $(n>2$ for $\mathrm{MnO}$ and $\mathrm{NiO}),{ }^{71}$ so the dispersion force is likely to be repulsive and insignificant for the current case. ${ }^{72,73}$ More importantly, we aimed to form SAFs well below the corresponding bulk solidus lines and prior studies suggested that the dispersion force is typically overwhelmed by the other (second) most common attractive interaction resulted from the $\Delta G_{\text {amorph }}^{\text {(vol) }} \cdot h$ term. ${ }^{28,66}$ Under such conditions, we can safely neglect the dispersion interaction. Then, we can introduce a thermodynamic parameter $(\lambda)$ to represent the thermodynamic tendency to stabilize a nanoscale SAF well below the bulk solidus line, as follows: ${ }^{74-76}$

$$
\lambda \equiv \frac{-\Delta \gamma}{\Delta G_{\mathrm{amorph}}^{(\mathrm{vol})}}
$$

The computed $\lambda$ scales the actual film thickness. In the current case, where the $\Delta G_{\text {amorph }}^{(\mathrm{vol})} \cdot h$ term is the dominant term that controls the film thickness well below the bulk solidus line, $\lambda$ can be used as a first-order estimate of the film thickness. More details about the derivation and justifications of this model and estimation method can be found in earlier studies of analogous subsolidus IGFs in metallic alloys, ${ }^{74-78}$ where the basic interfacial thermodynamic model and analysis methods are applicable to the current case.

To quantify $\Delta G_{\text {amorph }}^{(\mathrm{vol})}$ and accurately estimate the film thickness, we need full thermodynamic functions (typically from CALPHAD data) for the multicomponent systems involved, ${ }^{74-78}$ which are not available for the current case. However, we can roughly estimate this term by using a onecomponent equation, $\Delta G_{\text {amorph }}^{(\mathrm{vol})} \approx \Delta S_{\text {fusion }}^{(\mathrm{vol})} \Delta T$, where $\Delta S_{\text {fusion }}^{(\mathrm{vol})}$ is the volumetric fusion entropy and $\Delta T$ is the effective undercooling. There is no reported fusion entropy for $\mathrm{Li}_{3} \mathrm{PO}_{4}$. The fusion entropy is $\sim 23 \mathrm{~J} \mathrm{~mol}^{-1} \mathrm{~K}^{-1}$ for $\mathrm{K}_{3} \mathrm{PO}_{4}, \sim 33 \mathrm{~J} \mathrm{~mol}^{-1} \mathrm{~K}^{-1}$ for $\mathrm{H}_{3} \mathrm{PO}_{4}$, and $\sim 17 \mathrm{~J} \mathrm{~mol}^{-1} \mathrm{~K}^{-1}$ for $\mathrm{NaPO}_{3}$ (ref. 79); thus, we estimate the fusion entropy for $\mathrm{Li}_{3} \mathrm{PO}_{4}$ to be $\sim 15-35 \mathrm{~J} \mathrm{~mol}^{-1}$ $\mathrm{K}^{-1}$ (ref. 79), resulting in $\Delta S_{\text {fusion }}^{\text {(vol) }} \approx \sim 3-7 \times 10^{5} \mathrm{~J} \mathrm{~m}^{-3} \mathrm{~K}^{-1}$. The melting temperature for $\mathrm{Li}_{3} \mathrm{PO}_{4}$ is $1205{ }^{\circ} \mathrm{C}$ (ref. 80 and 81). We select annealing temperatures of $600-800{ }^{\circ} \mathrm{C}$ to form SAFs so that the effective $\Delta T \approx 400-600 \mathrm{~K}$ since there is no known intermediate compound or eutectic reaction in either binary system. Subsequently, $\Delta G_{\text {amorph }}^{(\mathrm{vol})}$ is estimated to be $\sim 1-4 \times$ $10^{8} \mathrm{~J} \mathrm{~m}^{-3}$, which is equivalent to an attractive pressure of 100-400 MPa that acts to thin the SAF; this estimate also further justifies that dispersion forces, which are typically on the order of $1-10 \mathrm{MPa}$ for similar cases, ${ }^{28,66}$ can be safely neglected for the current cases. The actual effective $\Delta T$ and $\Delta G_{\mathrm{amorph}}^{\text {(vol) }}$ can be reduced somewhat if there are some solubilities of other oxide components in the $\mathrm{Li}_{3} \mathrm{PO}_{4}$-based liquid or SAFs.

Eqn (2), (7) and Fig. 1(b) show that $\Delta G_{\text {amorph }}^{(\mathrm{vol} h}$ is the freeenergy penalty to form an SAF, which adds $0.1-0.4 \mathrm{~J} \mathrm{~m}^{-2}$ per nanometer (of the SAF thickness) to the total excess surface energy in eqn (3) or (6). The analysis above estimates the median value of $\Delta \gamma$ to $-0.7 \mathrm{~J} \mathrm{~m}^{-2}$, which provides the 
thermodynamic driving force that is significant enough for stabilizing an SAF (Fig. 1(b)). Combining the estimation of the driving force and penalty, eqn (8) produces an estimated $\lambda$ value of $\sim 2-7 \mathrm{~nm}$ (which may be somewhat greater if the actual effective $\Delta T$ is less). Furthermore, comparing eqn (7) and (8) produces: $h_{\mathrm{eq}}<\lambda \cdot f\left(h_{\mathrm{eq}}\right)$; thus, it is reasonable to estimate the actual equilibrium thickness to be in the low end of the estimated range of 2-7 $\mathrm{nm}$. In the experiments that will be presented subsequently, we have observed the formation of SAFs with equilibrium thicknesses of $\sim 2.9 \mathrm{~nm}$ and $\sim 2.5 \mathrm{~nm}$, respectively, for the two proof-of-concept systems, which are well consistent with the model prediction.

\section{Experimental}

\subsection{Materials synthesis}

To prepare $\mathrm{Li}_{3} \mathrm{PO}_{4}$-coated $\mathrm{LiCoO}_{2}, 2$ or 5 vol\% of $\mathrm{Li}_{3} \mathrm{PO}_{4}$ powder was added to $5 \mathrm{~g}$ of as-received $\mathrm{LiCoO}_{2}$ (Alfa Aesar, 99.5\%) and dispersed in $10 \mathrm{ml}$ of acetone; the mixture was placed in a silicon nitride grinding vial with two silicon nitride balls. Before sealing the jar, the corprene gasket was taped by Teflon to prevent it from acetone corrosion and precursor contamination. High energy ball milling was carried out using a SPEX 8000D mill for a duration of $10 \mathrm{~min}$ followed by a $15 \mathrm{~min}$ resting interval, and this milling process was repeated for 3 times. The mixture was dried in a vacuum oven. The dried powder was placed in a covered alumina crucible, isothermally annealed at $600{ }^{\circ} \mathrm{C}$ for $4 \mathrm{~h}$ in a box furnace with a heating rate of $5{ }^{\circ} \mathrm{C} \mathrm{min}^{-1}$, and air quenched. As a reference, controlled specimens of uncoated $\mathrm{LiCoO}_{2}$ were prepared using exactly the same ball milling and annealing procedures described above without the addition of $\mathrm{Li}_{3} \mathrm{PO}_{4}$.

$\mathrm{LiMn}_{1.5} \mathrm{Ni}_{0.5} \mathrm{O}_{4}$-based specimens were prepared using a similar procedure. To prepare the reference uncoated specimens, as-received $\mathrm{LiMn}_{1.5} \mathrm{Ni}_{0.5} \mathrm{O}_{4}$ (Sigma-Aldrich, >99\%) was ball milled for $60 \mathrm{~min}$, isothermally annealed at $800{ }^{\circ} \mathrm{C}$ for $8 \mathrm{~h}$ (with $5{ }^{\circ} \mathrm{C} \min ^{-1}$ heating rate), and quickly cooled down in the furnace with power shut down. $\mathrm{Li}_{3} \mathrm{PO}_{4}$-coated $\mathrm{LiMn}_{1.5} \mathrm{Ni}_{0.5} \mathrm{O}_{4}$ specimens were prepared by mixing 2 vol\% $\mathrm{Li}_{3} \mathrm{PO}_{4}$ with the pristine $\mathrm{LiMn}_{1.5} \mathrm{Ni}_{0.5} \mathrm{O}_{4}$, which were subsequently subjected to the exact same ball milling and heat treatment procedures. Since the as-received $\mathrm{LiMn}_{1.5} \mathrm{Ni}_{0.5} \mathrm{O}_{4}$ is non-uniform in particle size distribution and agglomerated, an additional reference $\mathrm{LiMn}_{1.5} \mathrm{Ni}_{0.5} \mathrm{O}_{4}$ specimen was prepared by annealing as-received $\mathrm{LiMn}_{1.5} \mathrm{Ni}_{0.5} \mathrm{O}_{4}$ at $800{ }^{\circ} \mathrm{C}$ for $8 \mathrm{~h}$ without prior ball milling.

\subsection{Material characterization}

X-ray diffraction (XRD) was carried out on a Scintag 2000 diffractometer using $\mathrm{Cu} \mathrm{K}_{\alpha}$ radiation $(\lambda=1.5418 \AA$ ) $)$ operating at $40 \mathrm{kV}$ and $35 \mathrm{~mA}$ with a step size of $0.02^{\circ}$ and a step time of $1 \mathrm{~s}$. Particle sizes and morphologies were characterized using a Hitachi 4800 scanning electron microscope (SEM). Particle surfaces were characterized by high-resolution transmission electron microscopy (HRTEM) using a Hitachi 9500 microscope. HRTEM specimens were prepared by dispersing powders ultrasonically in acetone and dropping a small amount of the suspension onto carbon coated copper grids; the specimens were then dried overnight in a desiccator. Minimum exposure was used during HRTEM to reduce electron beam damage. A large number of images of randomly-selected particle surfaces were recorded for each specimen for a fair statistical analysis.

\subsection{Electrochemical measurements}

To prepare cathodes, $80 \mathrm{wt} \%$ active materials, $15 \mathrm{wt} \%$ carbon black (MTI), 5 wt\% PVDF (MTI), and an appropriate amount of NMP (Alfa Aesar, anhydrous, 99.5\%) were mixed in a glass vial by a vibrating mixer, followed by further ultrasonic dispersion. The mixture was coated on an aluminum foil, which was subsequently dried in a vacuum oven at $120{ }^{\circ} \mathrm{C}$ for $12 \mathrm{~h}$. Cathode electrodes with a diameter of $10 \mathrm{~mm}$ were punched out, pressed at $\sim 187 \mathrm{MPa}$, and transferred into an Ar-filled glovebox for battery construction. Half cells were made using a cathode electrode, a metal Li chip (MTI, 99.9\%) as the anode, $1 \mathrm{M} \mathrm{LiPF}_{6}$ electrolyte, C480 separator (Celgard), and 2032 coin cell cases (SS304, MTI). The detailed procedure of assembling coin cells can be found in ref. 82. To make the electrolyte, EC/DEC/DMC (1:1:1 vol, BASF) solvent was used for $\mathrm{LiCoO}_{2}$ batteries that were charged up to $4.3 \mathrm{~V}$, and EC/DMC (1:1 vol, BASF) solvent was used for $\mathrm{LiCoO}_{2}$ batteries that were charged up to $4.5 \mathrm{~V}$ and $\mathrm{LiMn}_{1.5} \mathrm{Ni}_{0.5} \mathrm{O}_{4}$ batteries that were charged to $5.0 \mathrm{~V}$. To probe whether the interfacial polarization of the electrolyte near the particle surfaces is the rate control step in $\mathrm{LiCoO}_{2}$-based cathodes, we also prepared and tested coin cells using the $0.1 \mathrm{M} \mathrm{LiPF}_{6}$ electrolyte following a procedure developed by Creager and co-workers. ${ }^{55}$

Electrochemical cycling tests were carried out on an Arbin 2143 tester. The rate capabilities of $\mathrm{LiCoO}_{2}$ were tested at charge and discharge rates of $\mathrm{C} / 5$ for 4 cycles, followed by discharging at $1 \mathrm{C}, 2 \mathrm{C}, 5 \mathrm{C}, 10 \mathrm{C}$, and $25 \mathrm{C}$ sequentially (2 cycles at each discharge rate) while keeping the charge rate at $\mathrm{C} / 5$. An external pressure of $\sim 40 \mathrm{MPa}$ was added on coin cells during rate performance tests to reduce internal contact resistance. The rate performance of $\mathrm{LiMn}_{1.5} \mathrm{Ni}_{0.5} \mathrm{O}_{4}$ specimens was tested at the discharge rates of $\mathrm{C} / 5,1 \mathrm{C}, 5 \mathrm{C}, 25 \mathrm{C}, 45 \mathrm{C}, 65 \mathrm{C}$, and $85 \mathrm{C}$ sequentially (1 cycle at each discharge rate) with a constant charge rate of $\mathrm{C} / 5$. Before the rate performance test, all fresh $\mathrm{LiCoO}_{2}$ cells were charged and discharged at C/10 for 1 cycle and $\mathrm{C} / 5$ for 10 cycles to allow cells reaching a steady state. The cycling stability test of $\mathrm{LiCoO}_{2}$ was performed between $3.0 \mathrm{~V}$ and $4.5 \mathrm{~V}$ at a rate of $1 \mathrm{C}$ and room temperature after charging and discharging from $3 \mathrm{~V}$ to $4.2 \mathrm{~V}$ at a rate of $\mathrm{C} / 10$ for 1 cycle. The cycling stability of $\mathrm{LiMn}_{1.5} \mathrm{Ni}_{0.5} \mathrm{O}_{4}$ specimens was measured at a charge and discharge rate of $1 \mathrm{C}$ between $3.2 \mathrm{~V}$ and $5.0 \mathrm{~V}$ at an elevated temperature of $55 \pm 3{ }^{\circ} \mathrm{C}$ in an isothermal dry oven after first idling at $55 \pm 3{ }^{\circ} \mathrm{C}$ for $2 \mathrm{~h}$.

Cyclic voltammetry (CV) and electrochemical impedance spectroscopy (EIS) were performed using a Solartron 1287A/ 1255B analyzer. $\mathrm{CV}$ of $\mathrm{LiCoO}_{2}$ was performed between $3.3 \mathrm{~V}$ and $4.5 \mathrm{~V}$ at a scan rate of $0.1 \mathrm{mV} \mathrm{s}^{-1}$. Electrochemical impedance was measured from $1 \mathrm{MHz}$ to $0.05 \mathrm{~Hz}$ at $10 \mathrm{mV}$. Fresh cells of $\mathrm{LiCoO}_{2}$ with $\mathrm{Li}$ metal as the counter electrode were cycled for 
4 cycles at a rate of $\mathrm{C} / 5$ and finally charged to $4.2 \mathrm{~V}$ before the impedance measurements. Impedance measurements were also conducted for $\mathrm{LiMn}_{1.5} \mathrm{Ni}_{0.5} \mathrm{O}_{4}$ cells that were cycled at room temperature for 10 cycles (before the first measurement) and then cycled at $55 \pm 3{ }^{\circ} \mathrm{C}$ for 50 additional cycles (before the second measurement). All cells for impedance measurements were kept for more than $10 \mathrm{~h}$ after the charging to reach steady states.

\section{Results and discussion}

\section{1 $\mathrm{Li}_{3} \mathrm{PO}_{4}$-based equilibrium-thickness $\mathrm{SAFs}$ on $\mathrm{LiCoO}_{2}$}

XRD revealed only $\mathrm{LiCoO}_{2}$ peaks in both uncoated and 2 vol\% $\mathrm{Li}_{3} \mathrm{PO}_{4}$ coated $\mathrm{LiCoO}_{2}$ specimens (Fig. S1, ESI $\dagger$ ); some crystalline $\mathrm{Li}_{3} \mathrm{PO}_{4}$ phase might exist in the coated specimens as the secondary phase, but the amount and crystallinity were below the detection limit of XRD. SEM characterization showed that uncoated and 2 vol\% $\mathrm{Li}_{3} \mathrm{PO}_{4}$ coated $\mathrm{LiCoO}_{2}$ specimens have similar particle sizes on the order of $\sim 1 \mu \mathrm{m}$ (Fig. S2, ESI $\dagger$ ).
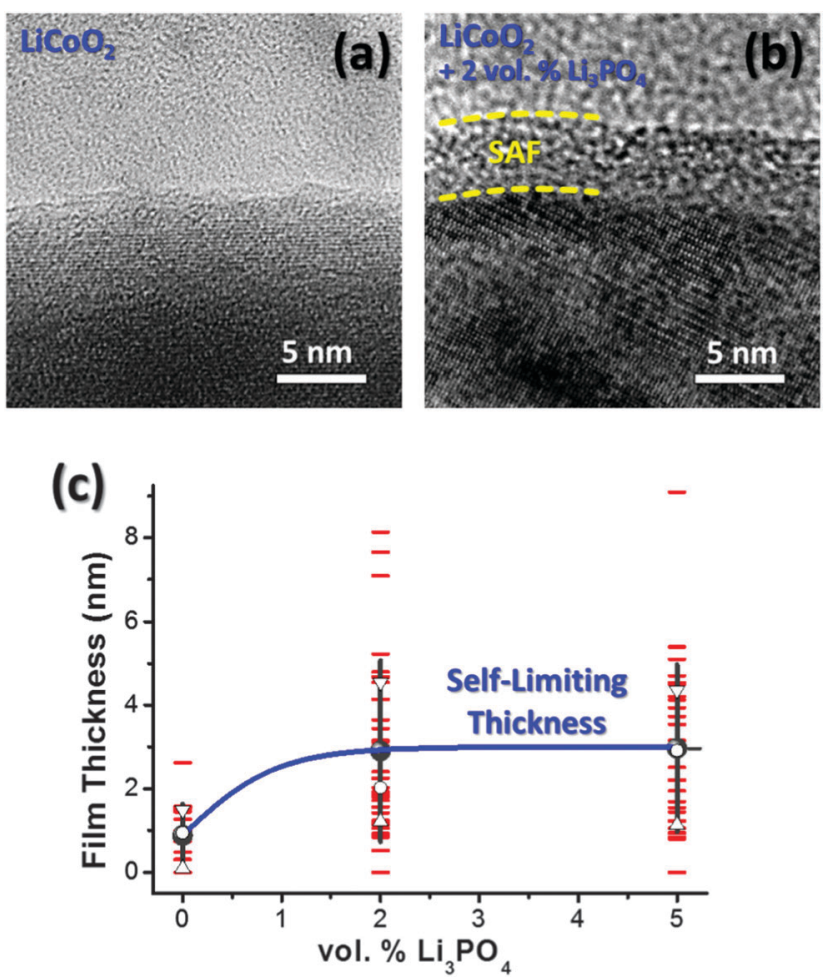

Fig. 2 Representative HRTEM images of the particle surfaces in (a) uncoated and (b) 2 vol\% $\mathrm{Li}_{3} \mathrm{PO}_{4}$ coated $\mathrm{LiCOO}_{2}$ specimens equilibrated at $600{ }^{\circ} \mathrm{C}$. (c) Measured film thickness vs. volume percentage of $\mathrm{Li}_{3} \mathrm{PO}_{4}$ added in $\mathrm{LiCOO}_{2}$ for specimens equilibrated at $600{ }^{\circ} \mathrm{C}$. Each horizontal bar represents the average thickness of an SAF formed on the surface of one particle (measured at multiple points around the particles and averaged). Each solid dot represents the measured mean thickness for the SAFs on all particle surfaces in a specimen and the connecting vertical bar represents \pm one standard deviation. Open circles, upper triangles and lower triangles, respectively, represent the medians, lower quartiles and upper quartiles, respectively. These SAFs exhibit a self-limiting thickness that is independent of the excess volume fraction of $\mathrm{Li}_{3} \mathrm{PO}_{4}$, after an equilibration is achieved, which unequivocally proved the existence of a thermodynamically-determined equilibrium thickness.
Thin layers were found on the surfaces of uncoated $\mathrm{LiCoO}_{2}$ particles, which were presumably $\mathrm{Li}_{2} \mathrm{CO}_{3}$ formed during annealing (that was commonly seen in prior studies ${ }^{29,83}$ ). As shown in Fig. 2, thicker and more uniform amorphous films were observed to form on particle surfaces of $\mathrm{Li}_{3} \mathrm{PO}_{4}$ added $\mathrm{LiCoO}_{2}$ specimens, in comparison with the reference uncoated $\mathrm{LiCoO}_{2}$ that had been subjected to the exactly the same milling and annealing conditions. The observed surface films in $\mathrm{Li}_{3} \mathrm{PO}_{4}$-coated $\mathrm{LiCoO}_{2}$ specimens appeared to be largely "amorphous" in HRTEM imaging (Fig. 2(b)), despite the equilibrium temperature $\left(600{ }^{\circ} \mathrm{C}\right)$ was likely well below the solidus temperature $\left(T_{\text {melt }}=1205{ }^{\circ} \mathrm{C}\right.$ for $\mathrm{Li}_{3} \mathrm{PO}_{4}$ according to ref. 80 and 81 and there is no known deep eutectic reaction between $\mathrm{Li}_{3} \mathrm{PO}_{4}$ and $\mathrm{LiCoO}_{2}$ ). As discussed in Section 2, the stabilization of the "amorphous" or quasi-liquid surface films with large structural disorder was likely driven by the $-\Delta \gamma$ term as the formation of crystalline surface films was frustrated by the high crystalcrystal interfacial energy that would occur.

To determine whether the observed SAFs have an equilibrium thickness, a large number of HRTEM images were recorded for randomly selected particle surfaces in three specimens (uncoated, 2 vol\% and 5 vol\% $\mathrm{Li}_{3} \mathrm{PO}_{4}$-coated $\mathrm{LiCoO}_{2}$ ) that were equilibrated at and quenched from $600{ }^{\circ} \mathrm{C}$, and careful statistical analysis was performed subsequently. The key results are summarized in Fig. 2(c). In the uncoated $\mathrm{LiCoO}_{2}$ specimen, surface (carbonate) films ( $>\sim 0.3 \mathrm{~nm}$ thick to be clearly discerned by HRTEM) were found on $\sim 78 \%$ particle surfaces among 18 surfaces characterized. The mean film thickness was measured to be $0.88 \mathrm{~nm}$ with a large relative standard deviation of $0.75 \mathrm{~nm}$; this specimen was referred to as "uncoated $\mathrm{LiCoO}_{2}$ " or " $\mathrm{LiCoO}_{2}$ without SAFs" interchangeably despite the presence of thin carbonate layers. Discernible SAFs were observed on 62 out of $64(\sim 97 \%)$ independent particle surfaces in the $\mathrm{Li}_{3} \mathrm{PO}_{4}$-coated $\mathrm{LiCoO}_{2}$ specimens. In the 2 vol\% $\mathrm{Li}_{3} \mathrm{PO}_{4}$ added $\mathrm{LiCoO}_{2}$ specimen, the mean film thickness was measured to be $2.90 \mathrm{~nm}$ with a standard deviation of $2.17 \mathrm{~nm}$ from a population of 35 independent particle surfaces characterized. When the addition of $\mathrm{Li}_{3} \mathrm{PO}_{4}$ was increased to $5 \mathrm{vol} \%$, the mean measured film thickness remained at $2.97 \mathrm{~nm}$ with a standard deviation of $2.00 \mathrm{~nm}$ (measured from 29 independent particle surfaces). The fact that the mean and distribution of the measured film thickness were independent of the extra amount of added $\mathrm{Li}_{3} \mathrm{PO}_{4}$ (2 vs. 5 vol\%) after reaching equilibration (Fig. 2(c)) unequivocally proved that these $\mathrm{Li}_{3} \mathrm{PO}_{4}$-based SAFs exhibited a self-limiting (equilibrium) thickness of $\sim 2.9 \mathrm{~nm}$, which was thermodynamically-determined (as discussed in Section 2).

As shown in Fig. 3(a), $\mathrm{Li}_{3} \mathrm{PO}_{4}$-based SAFs appreciably improved the rate performance of $\mathrm{LiCoO}_{2}$ for specimens tested in the normal $1 \mathrm{M}$ electrolyte. At $25 \mathrm{C}$, the average discharge capacity was measured to be $25.0 \mathrm{~mA} \mathrm{~h} \mathrm{~g}{ }^{-1}$ for the $\mathrm{LiCoO}_{2}$ specimen without SAFs, which was increased by $\sim 130 \%$ to $56.1 \mathrm{~mA} \mathrm{~h} \mathrm{~g}^{-1}$ in the 2 vol\% $\mathrm{Li}_{3} \mathrm{PO}_{4}$-coated $\mathrm{LiCoO}_{2}$ specimen with $\sim 2.9 \mathrm{~nm}$ thick SAFs. Since the SEM measurements showed that both specimens have comparable particles sizes (Fig. S2, ESI $\dagger$ ), the comparison of rate performances was fair. Interestingly, the average discharge capacity was measured to 

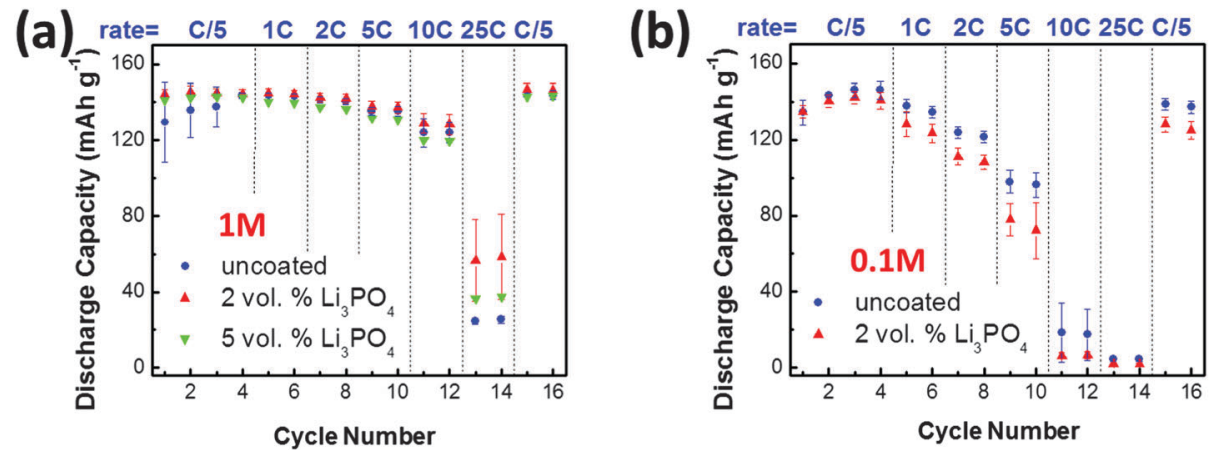

Fig. 3 Measured rate performance of uncoated and coated $\mathrm{LiCoO}_{2}$ at the electrolyte concentration of (a) $1 \mathrm{M}$ and (b) $0.1 \mathrm{M}$, respectively. Three coin cells were made and tested for each condition; the means are presented in the graphs and error bars represent \pm one standard deviations. All cells were charged at $\mathrm{C} / 5$ and discharged at various rates (labeled in the graphs) at room temperature.

be $37.0 \mathrm{~mA} \mathrm{~h} \mathrm{~g}{ }^{-1}$ for the 5 vol\% $\mathrm{Li}_{3} \mathrm{PO}_{4}$ added $\mathrm{LiCoO}_{2}$ specimen, which represented only a $\sim 50 \%$ increase from the uncoated specimen. This result suggested that adding extra amounts of $\mathrm{Li}_{3} \mathrm{PO}_{4}$ beyond that was needed for forming equilibrium-thickness SAFs provided no additional benefits; in fact, the extra $\mathrm{Li}_{3} \mathrm{PO}_{4}$ existed as a secondary phase, which might cause detrimental sintering and agglomeration effects during the $600{ }^{\circ} \mathrm{C}$ annealing. The substantial improvement of the rate performance was consistent with Sun and Dillon's prior results obtained in specimens quenched from $800{ }^{\circ} \mathrm{C}$ with thicker and non-uniform surficial films. ${ }^{22}$

Kang and Ceder proposed that the $\mathrm{Li}_{4} \mathrm{P}_{2} \mathrm{O}_{7}$-based surface phase improved the rate performance of one-dimensional ionic conducting $\mathrm{LiFePO}_{4}$ by enhancing fast surface ion conduction around the particle. ${ }^{52}$ Since $\mathrm{LiCoO}_{2}$ is a more isotropic twodimensional ion conductor, Sun and Dillon suspected that the enhanced rate performance was achieved by reducing concentration polarization of the electrolyte at the participle surfaces. ${ }^{22}$ In a recent work, Creager and co-workers ${ }^{55}$ suggested that if the interfacial concentration polarization was the rate limiting step, the benefit would be increased after intentionally lowering the concentration of the electrolyte. Following this idea, we tested our specimens with and without SAFs in the 0.1 $\mathrm{M} \mathrm{LiPF}_{6}$ electrolyte for a mechanistic study. As shown in Fig. 3(b), the SAFs became detrimental and lowered the discharge capacity at all rates. This result suggested that the concentration polarization of the electrolyte at the interface was not the rate limiting step for the current case according to Creager and co-workers' theory, ${ }^{55}$ though we should recognize that Sun and Dillon's specimens had thicker (but non-uniform) surficial films, which might exhibit a greater ability to reduce the concentration polarization of the electrolyte by creating a through-thickness lithium gradient in the film (that was $\sim 10 \mathrm{~nm}$ or $\sim 3 \times$ thicker, according to their HRTEM images) as they suspected. ${ }^{22}$

EIS measurements were carried out to further understand how SAFs improve the rate performance. The measured spectra are shown in Fig. 4(a) and fitted to an equivalent circuit shown in Fig. 4(b) that was proposed and tested by Liu and Manthiram. ${ }^{14}$ In this model (Fig $4(\mathrm{~b})$ ), $R_{\mathrm{O}}$ refers to the Ohmic resistance arising from the electrolyte, internal contact of

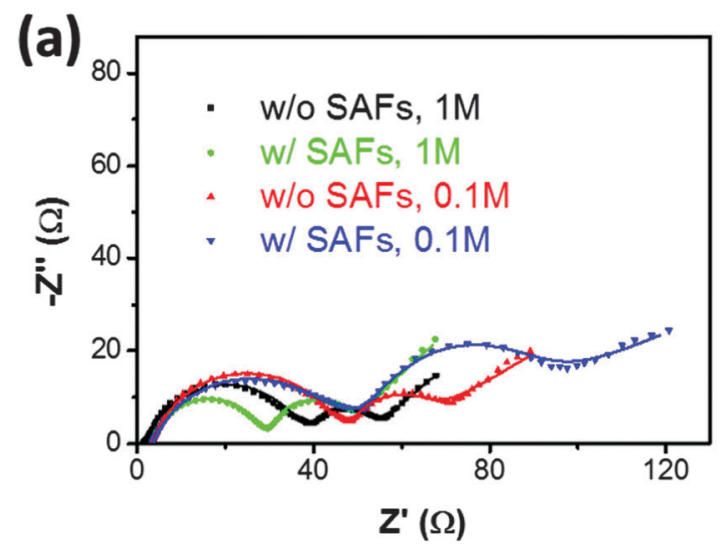

(b)

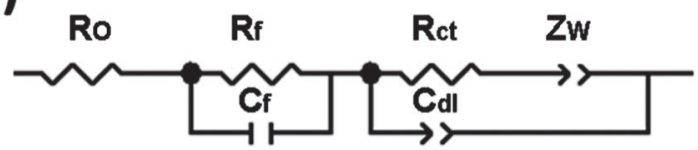

Fig. 4 (a) Measured electrochemical impedance spectra of the $\mathrm{LiCoO}_{2}$ specimens with and without $\mathrm{Li}_{3} \mathrm{PO}_{4}$-based SAFs, respectively, tested in $1 \mathrm{M}$ and $0.1 \mathrm{M}$ electrolytes, respectively. Dots represent experimental data and solid lines represent fitting curves using (b) an equivalent circuit model that was proposed by Liu and Manthiram. ${ }^{14}$

different cell parts, separator, and cell cases; $R_{\mathrm{f}}$ and $C_{\mathrm{f}}$ refer to film resistance and capacitance of SEI and SAFs, which produce the high-frequency semicircle in the spectra; $R_{\mathrm{ct}}$ and $C_{\mathrm{dl}}$ represent the charge transfer resistance and capacitance of the double layer, which produce the middle-frequency semicircle. The fitted $R_{\mathrm{f}}$ and $R_{\mathrm{ct}}$ values are summarized in Table 1 . It was found that the sum resistance of $R_{\mathrm{f}}$ and $R_{\mathrm{ct}}$ inversely correlated with the measured discharge capacities at $25 \mathrm{C}$ (by comparing the last two columns in Table 1), with the following order (decreasing rate performance or increasing $R_{\mathrm{f}}+R_{\mathrm{ct}}$ ): the coated cathode in the $1 \mathrm{M}$ electrolyte $>$ the uncoated cathode in the $1 \mathrm{M}$ electrolyte $>$ the uncoated cathode in the $0.1 \mathrm{M}$ electrolyte $>$ the coated sample cathode in the $1 \mathrm{M}$ electrolyte, which suggested that $\left(R_{\mathrm{f}}+R_{\mathrm{ct}}\right)$ might control the rate performance. If this was true, the EIS 
Table 1 Surface film resistance $\left(R_{\mathrm{f}}\right.$, which includes possible contributions from the SEI and SAFs) and charge transfer resistance $\left(R_{\mathrm{ct}}\right)$ of LiCoO specimens tested at the electrolyte concentration of $1 \mathrm{M}$ and $0.1 \mathrm{M}$. The average measured discharge capacities at $25 \mathrm{C}$ from Fig. 4 are also listed for comparison. The entries are sorted according to increasing total resistance $\left(R_{\mathrm{f}}+R_{\mathrm{ct}}\right)$, which is correlated with decreasing discharge capacity at $25 \mathrm{C}$

\begin{tabular}{llllrr}
\hline Specimen & $\begin{array}{l}\text { Electrolyte } \\
\text { concentration }(\mathrm{M})\end{array}$ & $R_{\mathrm{f}}(\Omega)$ & $R_{\text {ct }}(\Omega)$ & $R_{\mathrm{f}}+R_{\text {ct }}(\Omega)$ & $\begin{array}{l}\text { Discharge capacity } \\
\text { at } 25 \mathrm{C}\left(\mathrm{mA} \mathrm{h} \mathrm{g}^{-1}\right)\end{array}$ \\
\hline $\mathrm{LiCoO}_{2}$ with SAFs & 1 & $14.0 \pm 0.5$ & $26.0 \pm 0.2$ & 39.9 & 57.6 \\
$\mathrm{LiCoO}_{2}$ without SAFs & 1 & $11.0 \pm 1.2$ & $37.0 \pm 0.5$ & 48.1 & 25.0 \\
$\mathrm{LiCoO}_{2}$ without SAFs & 0.1 & $12.1 \pm 0.9$ & $42.2 \pm 0.5$ & 54.3 & 4.3 \\
$\mathrm{LiCoO}_{2}$ with SAFs & 0.1 & $24.4 \pm 0.7$ & $38.8 \pm 0.7$ & 63.2 & 2.0
\end{tabular}

measurements suggested that the formation of SAFs (at $\sim 97 \%$ of surfaces with an average thickness of $2.9 \mathrm{~nm}$ ) improved rate performance (at the normal electrolyte concentration of $1 \mathrm{M}$ ) largely by reducing interfacial charge transfer resistance $\left(R_{\mathrm{ct}}\right)$, as shown in Table 1.

It is well known that $\mathrm{LiCoO}_{2}$ exhibits good cycling stability at room temperature when it charged up to $4.2 \mathrm{~V}$, but the capacity fades when it is charged to a higher voltage (with the occurrence of a hexagonal-monoclinic-hexagonal phase transition accompanying anisotropic lattice distortion ${ }^{84}$ along with possibly more significant Co dissolution and HF corrosion). To investigate the effects of SAFs on capacity fading, we measured cycling performances of the $\mathrm{LiCoO}_{2}$ specimens with and without $\mathrm{Li}_{3} \mathrm{PO}_{4}$-based SAFs by charging and discharging between 3.0 and $4.5 \mathrm{~V}$ for 200 cycles. The measured results suggested that SAFs did appreciably reduce the capacity decaying (Fig. S3, ESI $\dagger$ ). It was presumed that SAFs protected the electrode by reducing HF attack and Co dissolution. In the current case, phase transitions and associated strains and fractures likely make significant contributions to the capacity fading, ${ }^{85}$ which are presumably less effected by SAFs; this is partially confirmed by CV studies of cycling stability mechanism described below.

As shown in Fig. 5(a), CV curves of $\mathrm{LiCoO}_{2}$ specimens with and without $\mathrm{Li}_{3} \mathrm{PO}_{4}$-based SAFs after the first cycle indicate that both materials underwent similar $\mathrm{Li}$ ion extraction/insertion and phase transition. Specifically, the peaks at $4.20 / 4.16 \mathrm{~V}$ corresponded to the phase transition with large lattice expansion, ${ }^{84}$ and Fig. 5(a) illustrated that $\mathrm{Li}_{3} \mathrm{PO}_{4}$-based SAFs had no effect on suppressing this phase transition. Fig. 5(b)-(d) displays the CV results of these two materials after 10,50 and 100 cycles, respectively. It was evident that the peak current of $\mathrm{LiCoO}_{2}$ with $\mathrm{Li}_{3} \mathrm{PO}_{4}$-based SAFs was higher than that of the reference $\mathrm{LiCoO}_{2}$ specimen without $\mathrm{Li}_{3} \mathrm{PO}_{4}$-based SAFs at all cycles, suggesting a protection effect from the SAFs; these CV results were consistent with cycling stability performance shown in Fig. S3 (ESI $\dagger$ ). Furthermore, the peak currents of both coated and uncoated $\mathrm{LiCoO}_{2}$ decreased with increasing number of cycles, indicating the performance decaying in both specimens; this was presumably due to the strain accumulation and possible micro-fractures for which SAFs would have little
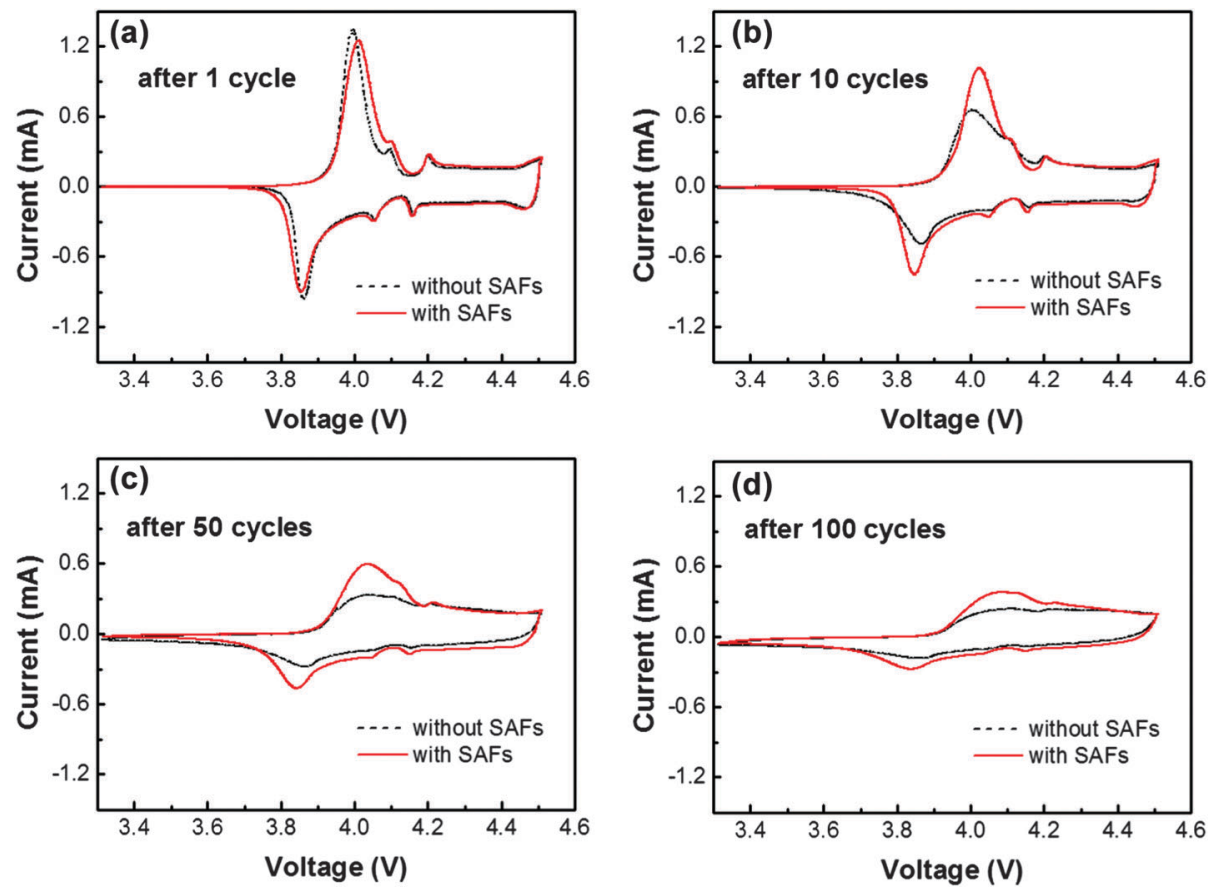

Fig. 5 Comparison of cyclic voltammograms of the $\mathrm{LiCoO}_{2}$ specimens with and without $\mathrm{Li}_{3} \mathrm{PO}_{4}$-based SAFs after (a) 1 cycle, (b) $10 \mathrm{cycles}$, (c) 50 cycles, and (d) 100 cycles, which were measured at a scan rate of $0.1 \mathrm{mV} \mathrm{s}^{-1}$ from $3.3 \mathrm{~V}$ to $4.5 \mathrm{~V}$. The first charge-discharge cycle was conducted from $3 \mathrm{~V}$ to $4.2 \mathrm{~V}$ at $\mathrm{C} / 10$, and the subsequent cycles were all conducted from $3 \mathrm{~V}$ to $4.5 \mathrm{~V}$ at $1 \mathrm{C}$. 
protection effect; these results were also consistent with the gradual decaying of discharge capacities for both materials (Fig. S3, ESI $\dagger$ ). Consequently, we conducted a more thorough study to examine the effects of $\mathrm{Li}_{3} \mathrm{PO}_{4}$-based SAFs on protecting $\mathrm{LiMn}_{1.5} \mathrm{Ni}_{0.5} \mathrm{O}_{4}$ at an elevated temperature, where HF attack and $\mathrm{Mn}$ dissolution are the major concerns (so SAF formation is more beneficial), which is described in the next section.

\section{2 $\mathrm{Li}_{3} \mathrm{PO}_{4}$-based equilibrium-thickness SAFs on} $\operatorname{LiMn}_{1.5} \mathrm{Ni}_{\mathbf{0 . 5}} \mathrm{O}_{4}$

XRD characterization of $\mathrm{LiMn}_{1.5} \mathrm{Ni}_{0.5} \mathrm{O}_{4}$ specimens revealed the presence of minor impurities of $\mathrm{Li}_{x} \mathrm{Ni}_{1-x} \mathrm{O}$ in the milled and annealed specimens (Fig. S4, ESI $\dagger$ ), the formation of which was reported in literature for specimens annealed under similar conditions. ${ }^{86} \mathrm{LiMn}_{1.5} \mathrm{Ni}_{0.5} \mathrm{O}_{4}$ was the majority phase (while the amount of $\mathrm{Li}_{x} \mathrm{Ni}_{1-x} \mathrm{O}$ was fairly minor) and no other impurity phase was detected by XRD (Fig. S4, ESI $\dagger$ ). Again, a minor secondary crystalline phase of $\mathrm{Li}_{3} \mathrm{PO}_{4}$ might be present in the $\mathrm{Li}_{3} \mathrm{PO}_{4}$ added specimens, but below the detection limit of XRD. SEM characterization showed that the particles were well dispersed with comparable and normal distributions of particle sizes (both about $1 \mu \mathrm{m}$ ) for uncoated and coated specimens after milling and annealing, even if the starting powder has a non-uniform particle size distribution and was agglomerated (Fig. S5, ESI $\dagger$ ).

HRTEM showed the formation of nanoscale $\mathrm{Li}_{3} \mathrm{PO}_{4}$-based SAFs in the 2 vol\% $\mathrm{Li}_{3} \mathrm{PO}_{4}$ added specimen, which appeared to be largely "amorphous" in HRTEM imaging (Fig. 6(b)); this was again consistent with the thermodynamic model presented in Section 2. The statistical results of the film thickness measurements are displayed in Fig. 6(c). On one hand, ultrathin surface
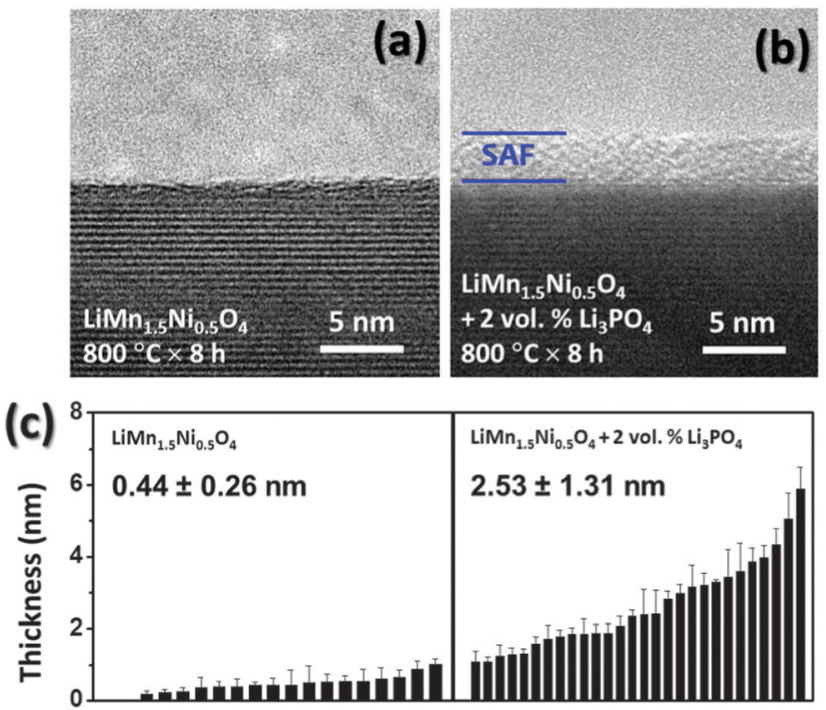

Fig. 6 Representative HRTEM images of the particle surfaces in the (a) $\mathrm{LiMn}_{1.5} \mathrm{Ni}_{0.5} \mathrm{O}_{4}$ and (b) $\mathrm{LiMn}_{1.5} \mathrm{Ni}_{0.5} \mathrm{O}_{4}+2$ vol\% $\mathrm{Li}_{3} \mathrm{PO}_{4}$ specimens that were ball milled and subsequently annealed at $800^{\circ} \mathrm{C}$ for $8 \mathrm{~h}$. (c) The corresponding distributions of measured thicknesses of the surface carbonate layers or $\mathrm{Li}_{3} \mathrm{PO}_{4}$-based SAFs for these two specimens, where each bar represents an average thickness measured from multiple points of one particle surface (and each error bar represents + one standard deviation of those multiple measurements, which signifies the uniformity of the surface film). layers were identified on 17 out of 19 particle surfaces in the reference uncoated specimen; the mean thickness was measured to be $0.44 \mathrm{~nm}$ with a standard deviation of $0.26 \mathrm{~nm}$, which was significantly thinner than the case of uncoated $\mathrm{LiCoO}_{2}$. Again, this specimen is referred to as "uncoated $\mathrm{LiMn}_{1.5} \mathrm{Ni}_{0.5} \mathrm{O}_{4}$ " or " $\mathrm{LiMn}_{1.5} \mathrm{Ni}_{0.5} \mathrm{O}_{4}$ without SAFs" in the following text despite the presence of thin layers of presumably carbonate. On the other hand, discernable SAFs were observed on 28 out of $29(\sim 97 \%)$ independent particle surfaces in the $2 \mathrm{vol} \% \mathrm{Li}_{3} \mathrm{PO}_{4}$ added $\mathrm{LiMn}_{1.5} \mathrm{Ni}_{0.5} \mathrm{O}_{4}$ specimen that was milled and annealed under identical conditions. The mean film thickness was measured to be $2.53 \mathrm{~nm}$ with a standard deviation of $1.31 \mathrm{~nm}$. The measured film thicknesses for the $\mathrm{Li}_{3} \mathrm{PO}_{4}$-coated $\mathrm{LiMn}_{1.5} \mathrm{Ni}_{0.5} \mathrm{O}_{4}$ specimen have a relative narrow distribution (given the possible broadening of the thickness distribution due to anisotropy, which is discussed below), indicating that equilibrium (constant) thicknesses were achieved for these $\mathrm{Li}_{3} \mathrm{PO}_{4}$-based SAFs.

It is important to note that all reported standard deviations in this study include variations in the equilibrium thicknesses due to anisotropic effects, i.e., the equilibrium thickness is a function of surface orientation as a result of anisotropy in surface/interface energies. Specifically, the surface energy of $\mathrm{LiMn}_{1.5} \mathrm{Ni}_{0.5} \mathrm{O}_{4}$ was computed to be $1.7 \mathrm{~J} \mathrm{~m}^{-2}$ for the (111) facet and $3.1 \mathrm{~J} \mathrm{~m}^{-2}$ for the (110) facet, ${ }^{69}$ suggesting significant anisotropy. The measured average thickness of $\sim 2.5 \mathrm{~nm}$ and standard deviation of $\sim 1.3 \mathrm{~nm}$ represent the overall mean and distribution of thicknesses for SAFs that form on all different surface orientations. The anisotropic formation and thicknesses of SAFs were reported for $\mathrm{Bi}_{2} \mathrm{O}_{3}$ on $\mathrm{ZnO}$ and $\mathrm{V}_{2} \mathrm{O}_{5}$ on $\mathrm{TiO}_{2}$ systems in prior studies. ${ }^{31,66}$

The rate performances of $\mathrm{LiMn}_{1.5} \mathrm{Ni}_{0.5} \mathrm{O}_{4}$ specimens with and without $\mathrm{Li}_{3} \mathrm{PO}_{4}$-based SAFs, which were subjected to identical milling and annealing conditions and have comparable particle sizes of $\sim 1 \mu \mathrm{m}$, are summarized in Table 2 . Representative discharging curves are displayed in Fig. 7. Similar to the case of $\mathrm{LiCoO}_{2}, \mathrm{Li}_{3} \mathrm{PO}_{4}$-based SAFs appreciably improved the rate performance of $\mathrm{LiMn}_{1.5} \mathrm{Ni}_{0.5} \mathrm{O}_{4}$ at all rates. The increases were $\sim 5-6 \%$ at $0.2-5 \mathrm{C}, \sim 40 \%$ at $25 \mathrm{C}$, and $\sim 360 \%$ at $45 \mathrm{C}$, respectively, which were presumably due to the formation of $\sim 2.5 \mathrm{~nm}$ thick $\mathrm{Li}_{3} \mathrm{PO}_{4}$-based SAFs. Small (but non-zero) discharge capacities of $\sim 15.4 \mathrm{~mA} \mathrm{~h} \mathrm{~g}^{-1}$ at $65 \mathrm{C}$ and $\sim 7.3 \mathrm{~mA} \mathrm{~h} \mathrm{~g}^{-1}$ at $85 \mathrm{C}$ were measured for the specimen with SAFs, while the capacity almost vanished for the specimen without SAFs at the same rates.

Table 2 Measured discharge capacities of the $\mathrm{LiMn}_{1.5} \mathrm{Ni}_{0.5} \mathrm{O}_{4}$ specimens with and without $\mathrm{Li}_{3} \mathrm{PO}_{4}$-based SAFs (which were subjected to the same milling and annealing treatment), along with the "annealed only" specimen without milling as an additional reference point

\begin{tabular}{|c|c|c|c|c|}
\hline \multirow[b]{2}{*}{ Rate } & \multicolumn{3}{|c|}{ Discharge capacity $\left(\mathrm{mA} \mathrm{h}^{-1}\right)$} & \multirow{2}{*}{$\begin{array}{l}\text { Increased percentage } \\
\text { with SAFs }(\%)\end{array}$} \\
\hline & Annealed only & Without SAFs & With SAFs & \\
\hline $\mathrm{C} / 5$ & $116.9 \pm 0.6$ & $110.5 \pm 0.1$ & $116.3 \pm 3.1$ & 5.2 \\
\hline $1 \mathrm{C}$ & $115.5 \pm 1.0$ & 109.2 & $114.5 \pm 3.3$ & 4.8 \\
\hline $5 \mathrm{C}$ & $99.6 \pm 8.4$ & $96.9 \pm 2.4$ & $102.6 \pm 6.1$ & 5.9 \\
\hline $25 \mathrm{C}$ & $58.3 \pm 6.0$ & $50.1 \pm 6.1$ & $70.7 \pm 7.1$ & 41 \\
\hline $45 \mathrm{C}$ & $8.7 \pm 5.7$ & $7.9 \pm 2.7$ & $36.3 \pm 7.9$ & $\sim 360$ \\
\hline $65 \mathrm{C}$ & $3.0 \pm 2.9$ & $2.2 \pm 1.0$ & $15.4 \pm 3.8$ & $\sim 600$ \\
\hline $85 \mathrm{C}$ & $1.3 \pm 1.3$ & $\sim 0.2$ & $7.3 \pm 2.0$ & - \\
\hline $\mathrm{C} / 5$ & $118.6 \pm 1.1$ & 112.4 & $118.1 \pm 2.3$ & 5.1 \\
\hline
\end{tabular}




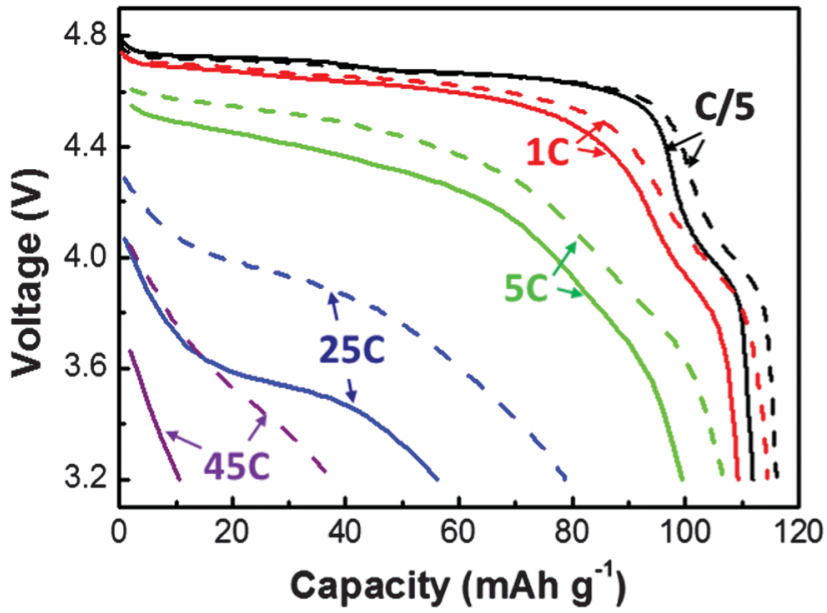

Fig. 7 Comparisons of discharge curves of $\mathrm{LiMn}_{1.5} \mathrm{Ni}_{0.5} \mathrm{O}_{4}$ specimens without (solid lines) and with (dash lines) $\mathrm{Li}_{3} \mathrm{PO}_{4}$-based SAFs. All cells were first charged and discharged at $\mathrm{C} / 10$ for 1 cycle and C/5 for 10 cycles to reach steady states before testing at the various discharge rates labeled in the graph.

At the same nominal rate of $25 \mathrm{C}$, the achieved discharge capacity with SAFs was $\sim 70.7 \mathrm{~mA} \mathrm{~h} \mathrm{~g}{ }^{-1}$ for the $\mathrm{LiMn}_{1.5} \mathrm{Ni}_{0.5} \mathrm{O}_{4}$ specimen with $\sim 2.5 \mathrm{~nm}$ thick $\mathrm{Li}_{3} \mathrm{PO}_{4}$-based SAFs, which was greater than the discharge capacity of $56.1 \mathrm{~mA} \mathrm{~h} \mathrm{~g}^{-1}$ for the $\mathrm{LiCoO}_{2}$ specimen with $\sim 2.9 \mathrm{~nm}$ thick $\mathrm{Li}_{3} \mathrm{PO}_{4}$-based SAFs, although the percentage increase was less $\left(\sim 40 \%\right.$ for $\mathrm{LiMn}_{1.5} \mathrm{Ni}_{0.5} \mathrm{O}_{4}$ vs. $\sim 130 \%$ for $\mathrm{LiCoO}_{2}$ with the SAF formation). $\mathrm{LiMn}_{1.5} \mathrm{Ni}_{0.5} \mathrm{O}_{4}$ has a cubic spinel structure, which is even more isotropic than the layered $\mathrm{LiCoO}_{2}$. The SAFs still enhanced the rate performance, suggesting that anisotropic ion conduction was not a necessary condition for SAFs to improve the rate performance. ${ }^{22,52}$

It is well-known that the high-voltage material $\mathrm{LiMn}_{1.5} \mathrm{Ni}_{0.5} \mathrm{O}_{4}$ is prone to capacity fading due to $\mathrm{Mn}$ dissolution and unstable SEI, particularly at elevated temperatures. ${ }^{87-89}$ We have measured the cycling stability at an elevated temperature of $55{ }^{\circ} \mathrm{C}$ (with a relatively high charge-discharge rate of $1 \mathrm{C}$ ) for five cells of $\mathrm{LiMn}_{1.5} \mathrm{Ni}_{0.5} \mathrm{O}_{4}$ specimens without $\mathrm{Li}_{3} \mathrm{PO}_{4}$-based SAFs and five cells of $\mathrm{LiMn}_{1.5} \mathrm{Ni}_{0.5} \mathrm{O}_{4}$ specimens without $\mathrm{Li}_{3} \mathrm{PO}_{4}$-based SAFs, respectively; the results clearly showed that the formation of $\mathrm{Li}_{3} \mathrm{PO}_{4}$-based SAFs reduced the capacity fading at $55{ }^{\circ} \mathrm{C}$ and improved cycling stability and consistence substantially. As shown in Fig. 8, all five cells of $\mathrm{LiMn}_{1.5} \mathrm{Ni}_{0.5} \mathrm{O}_{4}$ with $\mathrm{Li}_{3} \mathrm{PO}_{4}$-based SAFs produced very consistent and stable cycling behaviors. In contrast, the cycling behaviors of the $\mathrm{LiMn}_{1.5} \mathrm{Ni}_{0.5} \mathrm{O}_{4}$ specimens without $\mathrm{Li}_{3} \mathrm{PO}_{4}$-based SAFs (that was subjected to identical milling and annealing processes) showed large variations in their capacities and capacity fading rates. Two cells of the uncoated $\mathrm{LiMn}_{1.5} \mathrm{Ni}_{0.5} \mathrm{O}_{4}$ died after $\sim 150$ and $\sim 250$ cycles, respectively; other cells also exhibited lower capacities and greater capacity fading rates. Fig. 8 clearly shows that all five $\operatorname{LiMn}_{1.5} \mathrm{Ni}_{0.5} \mathrm{O}_{4}$ specimens with $\mathrm{Li}_{3} \mathrm{PO}_{4}$-based SAFs consistently exhibited more superior cycling stability than the five reference specimens without $\mathrm{Li}_{3} \mathrm{PO}_{4}$-based SAFs. Notably, the $\mathrm{LiMn}_{1.5} \mathrm{Ni}_{0.5} \mathrm{O}_{4}$ specimen with $\sim 2.5 \mathrm{~nm}$ thick SAFs retained $\sim 90 \mathrm{~mA} \mathrm{~h} \mathrm{~g}^{-1}$ or $\sim 80 \%$ of the initial capacity after 350 cycles at an elevated temperature of $55{ }^{\circ} \mathrm{C}$ and a relatively high charge-discharge rate of $1 \mathrm{C}$, which was an

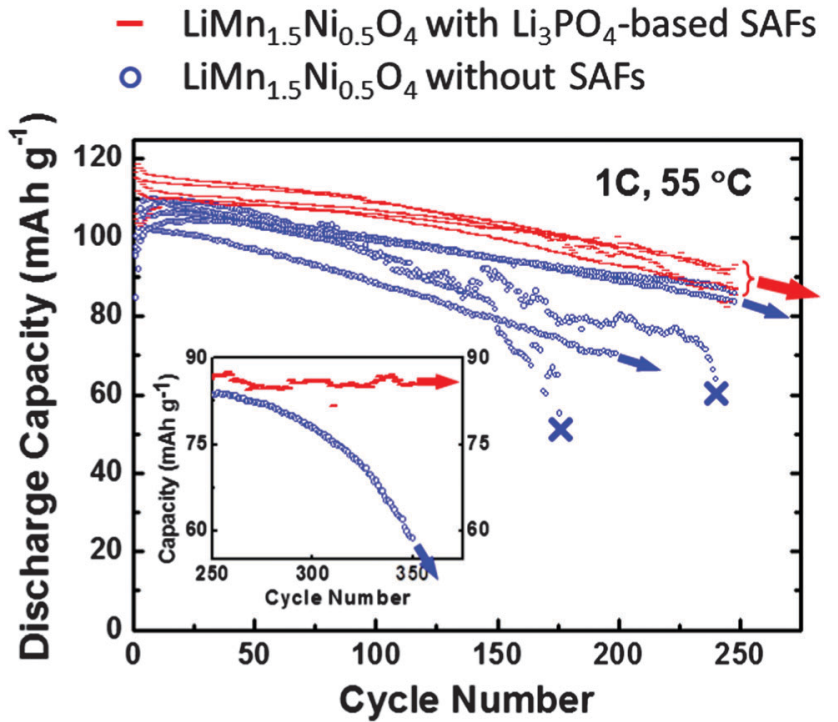

Fig. 8 Comparison of the cycling stabilities of five $\mathrm{LiMn}_{1.5} \mathrm{Ni}_{0.5} \mathrm{O}_{4}$ specimens without $\mathrm{Li}_{3} \mathrm{PO}_{4}$-based SAFs and five $\mathrm{LiMn}_{1.5} \mathrm{Ni}_{0.5} \mathrm{O}_{4}$ specimens with $\mathrm{Li}_{3} \mathrm{PO}_{4}$-based SAFs; all ten specimens were ball milled and subsequently annealed at $800{ }^{\circ} \mathrm{C}$ for $8 \mathrm{~h}$. All fresh cells were charged and discharged at $1 \mathrm{C}$ at $55^{\circ} \mathrm{C}$. " $\mathrm{X}$ " indicates that the battery died at that point.

exceptional performance. Fig. S6 (ESI $\dagger$ ) further showed that $\mathrm{LiMn}_{1.5} \mathrm{Ni}_{0.5} \mathrm{O}_{4}$ with $\sim 2.5 \mathrm{~nm}$ thick SAFs also performed better than the as-received $\mathrm{LiMn}_{1.5} \mathrm{Ni}_{0.5} \mathrm{O}_{4}$ and an additional reference specimen that was annealed at $800{ }^{\circ} \mathrm{C}$ without prior ball milling.

We further conducted EIS measurements to investigate how SAFs improved the cycling stability. Four electrochemical impedance spectra for the specimens with and without SAFs, respectively, after 10 cycles at room temperature (as the start point before raising the temperature) and after 50 additional cycles at an elevated temperature of $55{ }^{\circ} \mathrm{C}$, respectively, were collected and are shown in Fig. 9. The semicircles in the spectra

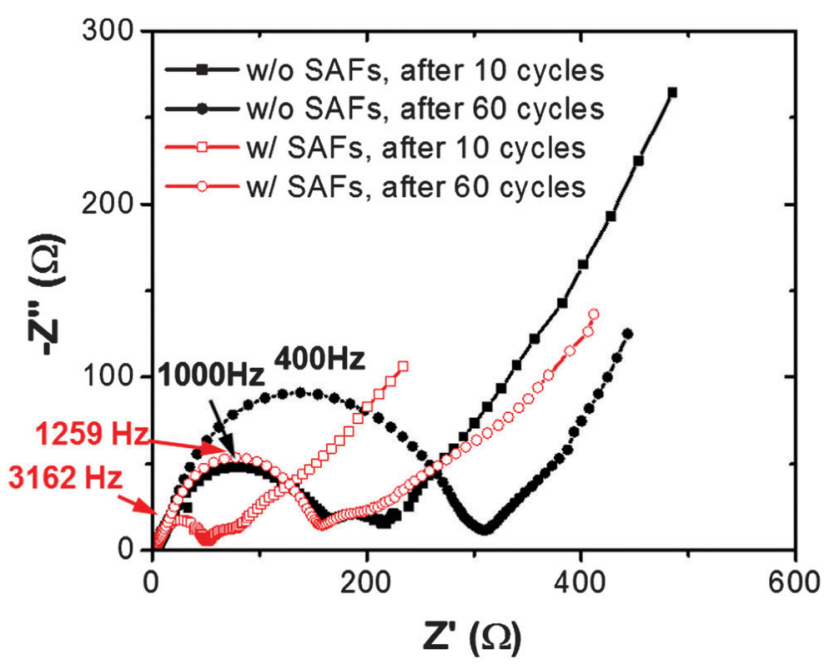

Fig. 9 Electrochemical impedance spectra of $\mathrm{LiMn}_{1.5} \mathrm{Ni}_{0.5} \mathrm{O}_{4}$ specimens with and without $\mathrm{Li}_{3} \mathrm{PO}_{4}$-based SAFs. Specimens were firstly charged and discharged at $1 \mathrm{C}$ for 10 cycles at room temperature followed by charging and discharging at $1 \mathrm{C}$ for 50 cycles at $55^{\circ} \mathrm{C}$. 
represented the responses from the film resistance, which were mainly contributed from the SEI formed during the cycling. While the film resistance should always increase with cycling due to the SEI formation, it was clearly evident from Fig. 9 that $\mathrm{Li}_{3} \mathrm{PO}_{4}$-based SAFs suppressed the growth of SEI, which was likely related to the improvement of the cycling stability at $55{ }^{\circ} \mathrm{C}$; presumably, this was because the $\mathrm{Li}_{3} \mathrm{PO}_{4}$-based SAFs protected the electrode surfaces from $\mathrm{HF}$ attacks and reduced Mn dissolution, which resulted in more stable SEI that grew slower with the high-temperature cycling. It is worth noting that Kobayashi et al. already showed that the formation of $\sim 100 \mathrm{~nm}$ thick $\mathrm{Li}_{3} \mathrm{PO}_{4}$ films on the surfaces of $\mathrm{LiMn}_{1.5} \mathrm{Ni}_{0.5} \mathrm{O}_{4}$ protected the electrode from reacting with the solid polymer electrolyte. ${ }^{99}$ In the current study, $\mathrm{Li}_{3} \mathrm{PO}_{4}$-based SAFs (surface coatings) formed spontaneously via a facile mixing and annealing process, with self-regulating (ultra-thin) thicknesses of 2-3 nm, which are significantly thinner than $\sim 100 \mathrm{~nm}$ thick $\mathrm{Li}_{3} \mathrm{PO}_{4}$ films made by electrostatic spray deposition in Kobayashi et al.'s study. Nonetheless, these ultra-thin SAFs protected the electrode surfaces while simultaneously improving the rate performance.

\section{Concluding remarks}

This study unequivocally demonstrated that equilibriumthickness SAFs can form spontaneously via a facile mixing and annealing method in selected systems and processing conditions that satisfy certain thermodynamic criteria. A thermodynamic framework is presented, which can be used to forecast the formation and stability of such nanoscale equilibrium-thickness SAFs in a broad range of battery electrode-coating systems if the relevant thermodynamic data are available or can be estimated. Using $\mathrm{Li}_{3} \mathrm{PO}_{4}$-based SAFs on $\mathrm{LiCoO}_{2}$ and $\mathrm{LiMn}_{1.5} \mathrm{Ni}_{0.5} \mathrm{O}_{4}$ as two proof-of-concept systems, we demonstrated that in each system/equilibrium condition, the spontaneously-formed SAFs formed uniformly (on $\sim 97 \%$ of surfaces) with rather a narrow distribution of film thicknesses (around the corresponding thermodynamically-determined "equilibrium" thickness). Adding extra film-forming materials beyond that was needed for forming equilibrium-thickness SAFs did not change the mean and distribution of the measured film thicknesses, which definitely proved that these SAFs have self-limiting (equilibrium) thickness.

The formation of SAFs significantly improved the rate performance and cycling stability of both $\mathrm{LiCoO}_{2}$ and $\mathrm{LiMn}_{1.5} \mathrm{Ni}_{0.5} \mathrm{O}_{4}$. At a high rate of $25 \mathrm{C}, \mathrm{SAF}$ formation improved the discharge capacity by $\sim 130 \%$ for $\mathrm{LiCoO}_{2}$ and by $\sim 40 \%$ for $\mathrm{LiMn}_{1.5} \mathrm{Ni}_{0.5} \mathrm{O}_{4}$, respectively. A specially-designed mechanistic study suggested that interfacial polarization of the electrolyte was not the rate-limiting step for $\mathrm{LiCoO}_{2}$ specimens, and EIS measurements further suggested that SAFs improved the rate performance of $\mathrm{LiCoO}_{2}$ by facilitating interfacial charge transfer. $\mathrm{Li}_{3} \mathrm{PO}_{4}$-based SAFs also significantly improved the cycling stability of both cathodes. With the formation of $\sim 2.5 \mathrm{~nm}$ thick equilibrium-thickness SAFs on the high-voltage material
$\mathrm{LiMn}_{1.5} \mathrm{Ni}_{0.5} \mathrm{O}_{4}$, a discharge capacity of $\sim 90 \mathrm{~mA} \mathrm{~h} \mathrm{~g}{ }^{-1}$ has been successfully retained after 350 cycles at an elevated temperature $55{ }^{\circ} \mathrm{C}$ and a relatively high charge-discharge rate of $1 \mathrm{C}$. EIS measurements suggested that $\mathrm{Li}_{3} \mathrm{PO}_{4}$-based SAFs reduced the capacity fading and improved the cycling stability and consistence by suppressing the SEI growth.

This study established a facile and generic surface modification method via an innovative use of equilibrium-thickness SAFs (a.k.a. a type of equilibrium surface "phases") to improve the performance of battery electrodes, and this method can be readily applied to many other cathode as well as anode materials. The key idea is to let thermodynamics make the uniform nanoscale coating for us. On the top of this, a potentiallytransformative concept is to utilize surface "phases" or complexions (equilibrium-thickness SAFs as only one example) to achieve superior structures and properties that are unattainable by using conventional bulk phases or normal materials fabrication methods. It is interesting to note that there was spot evidence in recent literature showing that facile heat treatments in controlled chemical environments can sometimes substantially improve the performance of both cathode $\mathrm{e}^{90-92}$ and anode $\mathrm{e}^{93-96}$ materials for lithium-ion batteries via the formation of surface defects or disordered structures including segregation or adsorption of impurity or doping species ${ }^{91-92,96}$ (and similar surface "phases" can also be utilized to improved other properties, e.g., catalytic and photocatalytic activities $^{31-32,97,98}$ ), though it was unknown whether equilibrium surface "phases" or complexions truly formed (and if so, what were their particular types and characters) in those cases. The success of the current study called for systematic and in-depth studies to explore the innovative concept of utilizing surface "phases" or complexions to achieve distinct surface structures with superior properties that may be unattainable otherwise.

\section{Acknowledgements}

This work is financially supported by an NSF grant no. DMR1006515/DMR-1320615 in the Ceramics program, managed by Dr Lynnette D. Madsen.

\section{Notes and references}

1 X. Meng, X.-Q. Yang and X. Sun, Adv. Mater., 2012, 24, 3589-3615.

2 L. A. Riley, S. Van Ana, A. S. Cavanagh, Y. Yan, S. M. George, P. Liu, A. C. Dillon and S.-H. Lee, J. Power Sources, 2011, 196, 3317-3324.

3 Y. S. Jung, A. S. Cavanagh, A. C. Dillon, M. D. Groner, S. M. George and S.-H. Lee, J. Electrochem. Soc., 2010, 157, A75-A81.

4 I. D. Scott, Y. S. Jung, A. S. Cavanagh, Y. An, A. C. Dillon, S. M. George and S.-H. Lee, Nano Lett., 2011, 11, 414-418.

5 D. Guan, J. A. Jeevarajan and Y. Wang, Nanoscale, 2011, 3, 1465-1469. 
6 J. Zhao and Y. Wang, J. Phys. Chem. C, 2012, 116, 11867-11876.

7 J. Zhao and Y. Wang, J. Solid State Electrochem., 2013, 17, 1049-1058.

8 J. Zhao and Y. Wang, Nano Energy, 2013, 2, 882-889.

9 C. Li, H. P. Zhang, L. J. Fu, H. Liu, Y. P. Wu, E. Ram, R. Holze and H. Q. Wu, Electrochim. Acta, 2006, 51, 3872-3883.

10 L. J. Fu, H. Liu, C. Li, Y. P. Wu, E. Rahm, R. Holze and H. Q. Wu, Solid State Sci., 2006, 8, 113-128.

11 J. Liu and A. Manthiram, J. Electrochem. Soc., 2009, 156, A833-A838.

12 J. Liu and A. Manthiram, J. Phys. Chem. C, 2009, 113, 15073-15079.

13 Q. Y. Wang, J. Liu, A. V. Murugan and A. Manthiram, J. Mater. Chem., 2009, 19, 4965-4972.

14 J. Liu and A. Manthiram, Chem. Mater., 2009, 21, 1695-1707.

15 Y. Wu and A. Manthiram, Solid State Ionics, 2009, 180, 50-56.

16 J. Liu and A. Manthiram, J. Electrochem. Soc., 2009, 156, A66-A72.

17 Y. Wu, A. V. Murugan and A. Manthiram, J. Electrochem. Soc., 2008, 155, A635-A641.

$18 \mathrm{Y}$. Wu and A. Manthiram, Electrochem. Solid-State Lett., 2006, 9, A221-A224.

19 A. M. Kannan, L. Rabenberg and A. Manthiram, Electrochem. Solid-State Lett., 2003, 6, A16-A18.

20 A. M. Kannan and A. Manthiram, Electrochem. Solid-State Lett., 2002, 5, A167-A169.

21 J. Cho, Y. J. Kim and B. Park, Chem. Mater., 2000, 12, 3788-3791.

22 K. Sun and S. J. Dillon, Electrochem. Commun., 2011, 13, 200-202.

23 J. Chong, S. D. Xun, X. Y. Song, G. Liu and V. S. Battaglia, Nano Energy, 2013, 2, 283-293.

24 T. F. Yi, X. Y. Li, H. P. Liu, J. Shu, Y. R. Zhu and R. S. Zhu, Ionics, 2012, 18, 529-539.

25 X. W. Li, R. Yang, B. Cheng, Q. Hao, H. Y. Xu, J. Yang and Y. T. Qian, Mater. Lett., 2012, 66, 168-171.

26 K. T. Lee, S. Jeong and J. Cho, Acc. Chem. Res., 2013, 46, 1161-1170.

27 T. F. Yi, Y. R. Zhu, X. D. Zhu, J. Shu, C. B. Yue and A. N. Zhou, Ionics, 2009, 15, 779-784.

28 J. Luo and Y.-M. Chiang, Annu. Rev. Mater. Res., 2008, 38, 227-249.

29 A. Kayyar, H. J. Qian and J. Luo, Appl. Phys. Lett., 2009, 95, 221905.

30 H. J. Qian, J. Luo and Y. M. Chiang, Acta Mater., 2008, 56, 862-873.

31 H. Qian and J. Luo, Acta Mater., 2008, 56, 4702-4714.

32 H. J. Qian and J. Luo, Appl. Phys. Lett., 2007, 91, 061909.

33 J. Luo, H. Wang and Y.-M. Chiang, J. Am. Ceram. Soc., 1999, 82, 916.

34 J. Luo and Y.-M. Chiang, J. Eur. Ceram. Soc., 1999, 19, 697-701.

35 M. Baram, D. Chatain and W. D. Kaplan, Science, 2011, 332, 206-209.
36 M. Baram and W. D. Kaplan, J. Mater. Sci., 2006, 41, 7775-7784.

37 D. R. Clarke, J. Am. Ceram. Soc., 1987, 70, 15-22.

38 R. M. Cannon and L. Esposito, Z. Metallkd., 1999, 90, 1002-1015.

39 J. Luo, Crit. Rev. Solid State Mater. Sci., 2007, 32, 67-109.

40 D. R. Clarke, T. M. Shaw, A. P. Philipse and R. G. Horn, J. Am. Ceram. Soc., 1993, 76, 1201-1204.

41 M. P. Harmer, Science, 2011, 332, 182-183.

42 M. Tang, W. C. Carter and R. M. Cannon, Phys. Rev. B: Condens. Matter Mater. Phys., 2006, 73, 024102.

43 W. D. Kaplan, D. Chatain, P. Wynblatt and W. C. Carter, J. Mater. Sci., 2013, 48, 5681-5717.

44 P. R. Cantwell, M. Tang, S. J. Dillon, J. Luo, G. S. Rohrer and M. P. Harmer, Acta Mater., 2014, 62, 1-48.

45 J. Luo, H. Cheng, K. M. Asl, C. J. Kiely and M. P. Harmer, Science, 2011, 333, 1730-1733.

46 S. J. Dillon, M. Tang, W. C. Carter and M. P. Harmer, Acta Mater., 2007, 55, 6208-6218.

47 W. Q. Li and S. H. Garofalini, J. Electrochem. Soc., 2005, 152, A364-A369.

48 G. J. Zhang, R. Yu, S. Vyas, J. Stettler, J. A. Reimer, G. Harley and L. C. De Jonghe, Solid State Ionics, 2008, 178, 1811-1816.

49 J. Chong, S. D. Xun, X. Y. Song, P. Ridgway, G. Liu and V. S. Battaglia, J. Power Sources, 2012, 200, 67-76.

50 J. Chong, S. Xun, X. Song, G. Liu and V. S. Battaglia, Nano Energy, 2013, 2, 283-293.

51 M. Tang, H. Y. Huang, N. Meethong, Y. H. Kao, W. C. Carter and Y. M. Chiang, Chem. Mater., 2009, 21, 1557-1571.

52 B. Kang and G. Ceder, Nature, 2009, 458, 190-193.

53 K. Zaghib, J. B. Goodenough, A. Mauger and C. Julien, J. Power Sources, 2009, 194, 1021-1023.

54 G. Ceder and B. Kang, J. Power Sources, 2009, 194, 1024-1028.

55 J. M. Oh, O. Geiculescu, D. DesMarteau and S. Creager, J. Electrochem. Soc., 2011, 158, A207-A213.

56 J. G. Dash and J. S. Wettlaufer, Phys. Rev. Lett., 2005, 94, 235301.

57 J. G. Dash, Contemp. Phys., 1989, 30, 89-100.

58 J. F. van der Veen, B. Pluis and A. W. Denier, in Chemistry and Physics of Solid Surfaces, ed. R. Vanselow and R. F. Howe, Springer, Berlin, 1988, vol. 7, pp. 455-467.

59 J. W. Cahn, J. Chem. Phys., 1977, 66, 3667-3672.

60 M. Tang, W. C. Carter and R. M. Cannon, Phys. Rev. Lett., 2006, 97, 075502.

61 J. Luo, M. Tang, R. M. Cannon, W. C. Carter and Y.-M. Chiang, Mater. Sci. Eng., A, 2006, 422, 19-28.

62 W. D. Kaplan and Y. Kauffmann, Annu. Rev. Mater. Res., 2006, 36, 1-48.

63 C. Li, L. Gu and J. Maier, Adv. Funct. Mater., 2012, 22, 1145-1149.

64 A. Schirmeisen, A. Taskiran, H. Fuchs, H. Bracht, S. Murugavel and B. Roling, Phys. Rev. Lett., 2007, 98, 225901.

65 M. Bobeth, D. R. Clarke and W. Pompe, J. Am. Ceram. Soc., 1999, 82, 1537-1546. 
66 J. Luo and Y.-M. Chiang, Acta Mater., 2000, 48, 4501-4515. 67 R. M. Cannon, M. Rühle, M. J. Hoffmann, R. H. French, H. Gu, A. P. Tomsia and E. Saiz, Ceram. Trans., 2000, 118, 427-444.

68 D. Kramer and G. Ceder, Chem. Mater., 2009, 21, 3799-3809. 69 E. Lee and K. A. Persson, Nanotechnology, 2013, 24, 424007.

70 N. D. Lepley, N. A. W. Holzwarth and Y. J. A. Du, Phys. Rev. B: Condens. Matter Mater. Phys., 2013, 88, 104103.

71 G. V. Samsonov, The Oxide Handbook, Plenum Data Company, New York, 1982.

72 R. H. French, V. A. Parsegian, R. Podgornik, R. F. Rajter, A. Jagota, J. Luo, D. Asthagiri, M. K. Chaudhury, Y. M. Chiang, S. Granick, S. Kalinin, M. Kardar, R. Kjellander, D. C. Langreth, J. Lewis, S. Lustig, D. Wesolowski, J. S. Wettlaufer, W. Y. Ching, M. Finnis, F. Houlihan, O. A. von Lilienfeld, C. J. van Oss and T. Zemb, Rev. Mod. Phys., 2010, 82, 1887-1944.

73 R. H. French, J. Am. Ceram. Soc., 2000, 83, 2117-2146.

74 J. Luo, J. Am. Ceram. Soc., 2012, 95, 2358-2371.

75 X. Shi and J. Luo, Phys. Rev. B: Condens. Matter Mater. Phys., 2011, 84, 014105.

76 J. Luo and X. M. Shi, Appl. Phys. Lett., 2008, 92, 101901.

77 X. Shi and J. Luo, Phys. Rev. Lett., 2010, 105, 236102.

78 J. Luo, Curr. Opin. Solid State Mater. Sci., 2008, 12, 81-88.

79 B. E. Poling, G. H. Thomson, D. G. Friend, R. L. Rowley and W. V. Wilding, Perry's Chemical Engineers' Handbook, The McGraw-Hill Companies, 2008.

80 L. N. Ji, J. B. Li, Y. Q. Chen, J. Luo, J. K. Liang and G. H. Rao, J. Alloys Compd., 2009, 486, 352-356.

81 J. Nakano, T. Yamada and S. Miyazawa, J. Am. Ceram. Soc., 1979, 62, 465-467.

82 A. Kayyar, J. Huang, M. Samiee and J. Luo, J. Visualized Exp., 2012, e4104.

83 D. Aurbach, B. Markovsky, M. D. Levi, E. Levi, A. Schechter, M. Moshkovich and Y. Cohen, J. Power Sources, 1999, 81, 95-111.
84 J. N. Reimers and J. R. Dahn, J. Electrochem. Soc., 1992, 139, 2091-2097.

85 H. F. Wang, Y. I. Jang, B. Y. Huang, D. R. Sadoway and Y. M. Chiang, J. Electrochem. Soc., 1999, 146, 473-480.

86 F. G. B. Ooms, E. M. Kelder, J. Schoonman, M. Wagemaker and F. M. Mulder, Solid State Ionics, 2002, 152, 143-153.

87 W. Choi and A. Manthiram, J. Electrochem. Soc., 2006, 153, A1760-A1764.

88 T. F. Yi, Y. Xie, M. F. Ye, L. J. Jiang, R. S. Zhu and Y. R. Zhu, Ionics, 2011, 17, 383-389.

89 D. Liu, W. Zhu, J. Trottier, C. Gagnon, F. Barray, A. Guerfi, A. Mauger, H. Groult, C. M. Julien, J. B. Goodenough and K. Zaghi, RSC Adv., 2014, 4, 154-167.

90 D. W. Liu, Y. Y. Liu, A. Q. Pan, K. P. Nagle, G. T. Seidler, Y. H. Jeong and G. Z. Cao, J. Phys. Chem. C, 2011, 115, 4959-4965.

91 D. W. Shin, C. A. Bridges, A. Huq, M. P. Paranthaman and A. Manthiram, Chem. Mater., 2012, 24, 3720-3731.

92 D. W. Shin and A. Manthiram, Electrochem. Commun., 2011, 13, 1213-1216.

93 K.-S. Park, A. Benayad, D.-J. Kang and S.-G. Doo, J. Am. Chem. Soc., 2008, 130, 14930-14931.

94 K. S. Han, J. W. Lee, Y. M. Kang, J. Y. Lee and J. K. Kang, Small, 2008, 4, 1682-1686.

95 H. Han, T. Song, J.-Y. Bae, L. F. Nazar, H. Kim and U. Paik, Energy Environ. Sci., 2011, 4, 4532-4536.

96 M. Samiee and J. Luo, J. Power Sources, 2014, 245, 594-598.

97 X. B. Chen, L. Liu, P. Y. Yu and S. S. Mao, Science, 2011, 331, 746-750.

98 M. Samiee and J. Luo, Mater. Lett., 2013, 98, 205-208.

99 Y. Kobayashi, H. Miyashiro, K. Takei, H. Shigemura, M. Tabuchi, H. Kageyama and T. Iwahori, J. Electrochem. Soc., 2003, 150, A1577-A1582. 